NBER WORKING PAPER SERIES

\title{
OPPOSITION MEDIA, STATE CENSORSHIP, AND POLITICAL ACCOUNTABILITY: EVIDENCE FROM CHAVEZ'S VENEZUELA
}

\author{
Brian Knight \\ Ana Tribin \\ Working Paper 25916 \\ http://www.nber.org/papers/w25916 \\ NATIONAL BUREAU OF ECONOMIC RESEARCH \\ 1050 Massachusetts Avenue \\ Cambridge, MA 02138 \\ June 2019, Revised October 2019
}

The opinions and statements are the sole responsibility of the authors and do not necessarily represent those of the Banco de la República, its Board of Directors, or the National Bureau of Economic Research. We thank audiences at Columbia University, Harvard University, London School of Economics, Nottingham University, University of Warwick, and the New York City Media Seminar. Julia Cage, Greg Martin, Adam Szeidl, Ferenc Szucs, and Maria Petrova provided helpful comments.

NBER working papers are circulated for discussion and comment purposes. They have not been peer-reviewed or been subject to the review by the NBER Board of Directors that accompanies official NBER publications.

(C) 2019 by Brian Knight and Ana Tribin. All rights reserved. Short sections of text, not to exceed two paragraphs, may be quoted without explicit permission provided that full credit, including () notice, is given to the source. 
Opposition Media, State Censorship, and Political Accountability: Evidence from Chavez's

Venezuela

Brian Knight and Ana Tribin

NBER Working Paper No. 25916

June 2019, Revised October 2019

JEL No. D7,D8

\begin{abstract}
This paper investigates the effects of state censorship of opposition media using evidence from the closing of RCTV, a popular opposition television channel in Venezuela. The government did not renew RCTV's license, and the channel was replaced overnight, during May 2007, by a progovernment channel. Based upon this censorship of opposition television, we have three key findings. First, using Nielsen ratings data, viewership fell, following the closing of RCTV, on the pro-government replacement, but rose on Globovision, the only remaining television channel for opposition viewers. This finding is consistent with a model in which viewers have a preference for opposition television and substitute accordingly. Second, exploiting the geographic location of the Globovision broadcast towers, Chavez approval ratings fell following the closing of RCTV in places with access to the Globovision signal, relative to places without access. Third, in places with access to the Globovision signal, relative to places without, support for Chavez in electoral data also fell following the closing of RCTV. Counterfactuals, which account for both substitution patterns in media consumption and the persuasive effects of opposition television, document that switching to uncensored outlets led to an economically significant reduction in support for Chavez.
\end{abstract}

Brian Knight

Brown University

Department of Economics, Box B

64 Waterman Street

Providence, RI 02912

and NBER

Brian_Knight@brown.edu

Ana Tribin

Central Bank of Colombia

Bogota, Colombia

atribiur@banrep.gov.co 


\section{Introduction}

Opposition media has the potential to help voters hold incumbent politicians and parties accountable. By reporting on the performance of government, including coverage of scandals and corruption, the media provides information to voters that is useful when deciding whether or not to re-elect incumbent politicians and parties $1^{1}$ In this way, the media also provides incentives for officials to act in the best interests of their

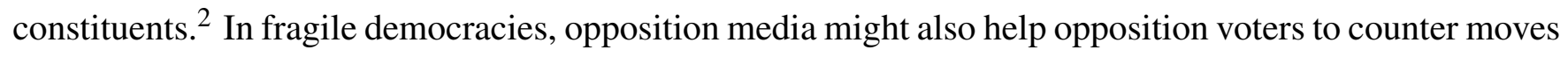
towards authoritarianism and to facilitate collective action against the government.

Despite these potential benefits of opposition media to society, incumbent governments, given the threats to their power, face incentives to limit press scrutiny of their office. These limitations on opposition media may take a variety of forms, from licensing requirements to restricting access to government officials to outright censorship. Censorship itself can be manifested in variety of ways, from the closing of opposition media outlets to content requirements to the outright blocking of specific media reports.

When the government censors opposition media, what are the effects on support for incumbent politicians? Is censorship effective? And how does the answer to this question depend upon how voters respond to censorship? Possible responses by voters include discounting, by which rational voters may simply account for censorship when processing content, understanding that censorship implies a loss of access to information that might reflect negatively on the government. This type of discounting should reduce the impact of censorship (Chiang and Knight (2011)). Even in the absence of discounting, however, opposition voters might respond to censorship and the associated change in ideological content by switching away from censored outlets and towards other opposition outlets when available (Durante and Knight (2012)). Moreover, if other opposition outlets are not available, viewers can respond to censorship by simply tuning out, reducing their overall media consumption (Knight and Tribin (2019)). By processing information in a sophisticated way and by adjusting their media consumption patterns, voters can limit the effectiveness of government censorship of opposition media outlets.

We investigate these issues in the setting of Venezuela during the Presidency of Hugo Chavez. In particular, we examine the effects of the Chavez government closing RCTV, a popular opposition television channel with national coverage, on support for Chavez. The change occurred overnight, on May 27, 2007, following the expiration of RCTV's 20-year broadcast license and the government's decision to not renew the license. The government replaced RCTV with a pro-government public channel, TVES, which inher-

\footnotetext{
${ }^{1}$ On media coverage of government performance, see, among others, Ferraz and Finan (2008)

${ }^{2}$ On these incentives provided by media coverage, see, among others, Besley and Burgess (2002) and Ferraz and Finan (2011).
} 
ited both the channel number and the broadcast infrastructure of RCTV. Two large metro areas, Caracas and Valencia, retained access to opposition television via Globovision, the remaining source of opposition news available via broadcast signal following the closing of RCTV, while the remainder of the country no longer had access to opposition television via broadcast signal. We incorporate information on the Globovision broadcast towers and, using the Irregular Terrain Model, predict the strength of the Globovision broadcast signal across municipalities. While the Globovision signal is not randomly assigned, the timing of the 20-year broadcast license expiring is arguably random. Given this, our key identifying assumption is that trends in support for Chavez in areas with the Globovision signal would have followed trends in support in areas without the signal following the closing of RCTV.

Based upon an analysis of this intervention, we have three key findings. First, using Nielsen ratings data, we find that viewers responded strongly, in terms of adjusting their media consumption patterns, to the change in ideological content. In particular, we find a sharp reduction in viewership of TVES, relative to RCTV, following the change. Likewise, we find a corresponding increase in viewership of Globovision, the remaining opposition television channel, in the two metro areas with access to the broadcast signal. Taken together, these two findings suggest that voters respond to censorship of opposition media outlets by switching to other opposition channels when available.

Second, using geographic variation in the Globovision signal across municipalities, we examine annual survey data (Latin Barometer) conducted both before and after the closing of RCTV. In particular, we document a reduction in approval ratings for Chavez in those municipalities with access to the Globovision signal, relative to municipalities without such access, following the closing of RCTV. Addressing possible threats to our identifying assumption, we show that these results are robust to observable controls and an analysis that focuses on the narrow geographic region surrounding the Caracas and Valencia metro areas. Further, placebo timing specifications document a key shift in 2007, the year that RCTV closed. We also show that our results cannot be explained by trends in internet use, a potential alternative explanation. Finally, in a further investigation of dynamics, we find that the effects tend to fade over time, as access to the Globovision signal matters less towards the end of our sample period when compared to the period just following the closing of RCTV.

Third, we document similar patterns in municipality-level electoral returns data covering two elections prior to the closing of RCTV and three elections following the closing of RCTV. In particular, we find a reduction in the Chavez vote share in municipalities with access to the Globovision signal, relative to municipalities without the signal, following the closing of RCTV. These results are again robust to an analysis that focuses on the geographic region surrounding Caracas and Valencia, and, likewise, placebo 
timing specifications document a key shift in 2007, the year that RCTV closed. Similarly to the results for approval ratings, these effects tend to fade over time, as access to the Globovision signal matters less towards the end of our sample period, when compared to the period just following the closing of RCTV.

Combining all of these results, we then conduct counterfactuals that account for both substitution patterns in media consumption and the persuasive effects of opposition television. Comparing our baseline results to a no-switching counterfactual, we document that switching to uncensored outlets led to an economically significant reduction in support for Chavez. We also analyze a counterfactual in which both RCTV and Globovision are closed, leading to significant increases in support for Chavez in areas with access to the Globovision signal, relative to areas without this access.

Taken together, these findings suggest that viewers with access to the broadcast signal increased their viewership of Globovision, leading to a reduction in support for Chavez, relative to viewers in areas that no longer had access to opposition television via broadcast signal, following the closing of RCTV. Thus, censorship appears to have increased support for the Chavez government in areas without access to other opposition television channels, relative to areas that retained access to opposition television. This suggests that behavioral changes in media consumption patterns are an effective response to censorship. Yet these differences across municipalities fade over time, suggesting that viewers in areas without other opposition channels might adjust to their new media environment and discount censored material accordingly. We formalize these ideas in the context of a model of an informative media and government censorship of negative media reports. In the model, voters account for censorship when processing of media reports and have a preference for opposition media. While voters might be manipulated by censorship in the short run, they discount appropriately in the long run after learning about the censorship environment from the lack of negative media reports about the government.

The paper proceeds as follows. We next review the relevant literature and then provide a more detailed overview of the setting. We then describe our empirical results regarding changes in viewership, approval ratings, and electoral returns. Following a theoretical explanation for these results, the final section concludes.

\section{Related Literature}

This paper comes at the intersection of two literatures on the political economy of the media, one involving media consumption patterns according to ideology and another involving the persuasive effects of the media. Studies on media consumption patterns include Durante and Knight (2012), who show that 
right-leaning viewers were more likely to watch public television during periods in which it was controlled by Silvio Berlusconi, the leader of the center-right coalition in Italy during the 1990s and early 2000s. Likewise, Knight and Tribin (2019), also using data from Venezuela, examine high frequency changes in ratings for news programs that are interrupted by cadenas, government propaganda that is not announced in advance to stations and viewers. The key finding is that the drop-off in ratings is particularly pronounced on opposition-aligned channels when they are airing news programming, consistent with a preference for like-minded information (Gentzkow and Shapiro (2010) and Mullainathan and Shleifer (2005)). In the U.S. context, Martin and McCrain (2019) document small decreases in viewership following the acquisition of local television stations by a national conglomerate (Sinclair). Taken together, these studies document that viewers are not passive receivers of information and instead respond to changes in ideological content, both in the short run and in the longer run.

On the persuasive effects of opposition media and state censorship, Enikolopov, Petrova and Zhuravskaya (2011) find that access to opposition media in Russia reduced support for the incumbent government. Adena et al. (2015) document that government-controlled radio facilitated the rise of Nazi party in Germany during the 1930s. Chen and Yang (2019) conduct a field experiment in which students in China are provided free access to the uncensored internet. When combined with encouragement, acquisition of information increases, leading to changes in knowledge, beliefs, and attitudes ${ }^{3}$ Roberts (2018) covers censorship in China, arguing that inconveniencing users for accessing information is an important form of censorship. She also draws an important distinction between observed and unobserved censorship. In our setting, the closing of RCTV was widely observed, making it easier for voters to adjust to the new media environment.

While there are only a few empirical studies on the persuasive effects of censorship, there is of course a large and active literature, more generally, on the persuasive effects of media bias. Evidence that biased outlets may influence voting outcomes include Durante, Pinotti and Tesei (2017), DellaVigna and Kaplan (2007), George and Waldfogel (2003), Gentzkow, Shapiro and Sinkinson (2011), Gerber, Karlan and Bergan (2009), Martin and Yurukoglu (2017), Prat (2018), and Snyder and Stromberg (2010). Chiang and Knight (2011) argue that any persuasive effects of bias might be limited by voter discounting. In particular, based upon responses to newspaper endorsements in U.S. Presidential elections, voters appear to discount biased information. That is, cross-over endorsements, those for Republican candidates from left-leaning

\footnotetext{
${ }^{3}$ Regarding the supply side, King, Pan and Roberts (2013) show that censors in China allow a significant amount of controversial material on social media to go uncensored but are particularly likely to block posts facilitating collective action. Consistent with this idea, Enikolopov et al. (2019) document that social media availability plays a key role in protest activity against the government in Russia.
} 
papers and for Democratic candidates from right-leaning papers, are more influential than less surprising endorsements, those for Republican candidates from right-leaning papers and for Democratic candidates from left-leaning papers. This limits the influence of media bias in the sense that shifting a newspaper's ideology towards the right reduces the electoral impact of an endorsement of a Republican candidate by that newspaper.

Relative to these two literatures, our paper is one of the first to simultaneously consider media consumption and persuasion. The key advantage of this approach is that we can quantify the degree to which behavioral responses by consumers, switching to non-censored outlets when available, limit the persuasive effects of censorship. That is, our paper conducts counterfactuals in which we measure the persuasive effects of censorship under counterfactual media consumption environments, including one in which viewers do not switch to non-censored outlets and another in which both Globovision and RCTV are closed. These approaches are only possible via our simultaneous consideration of media consumption and persuasion in the same setting.

The only other paper of which we are aware to simultaneously consider media consumption and persuasion is Martin and Yurukoglu (2017), who study these issues in the context of cable TV news in the U.S. One finding is that the media may lead to increased polarization via a feedback loop, with Fox News, for example, shifting viewer ideology towards the right, further increasing their preference for right-leaning content. Our results, by contrast, document that the electoral effects of censorship, if anything seem to fade over time. We argue that this is consistent with a model in which viewers learn about both government performance and the censorship environment from news reports. While censorship might be effective in the short run, viewers learn about the degree of censorship over time and discount accordingly. That is, voters recognize that censorship entails a loss of information that might reflect negatively upon the government. Due to this learning and discounting, the effects of censorship may tend to fade over time.

Our study is also closely related to independent work by Kronick and Marshall (2018), who, like us, study the electoral effects of the closing of RCTV in Venezuela. Their comparison is between areas with significant cable penetration (RCTV re-emerged on cable later in 2007) and areas without significant cable penetration, the idea being that areas with access to cable are less influenced by the closing of RCTV, when compared to areas with less access to cable. Relative to our study, their geographic variation is more finegrained. In particular, while our analysis uses municipalities as the unit of observation, they use polling stations as the unit of observation and exploit variation across these smaller geographic units and within parishes (geographic units that are larger than polling stations and smaller than municipalities). They study electoral returns and find that retaining access to RCTV via cable access led to a relative increase 
in support for Chavez. They argue that this finding is consistent with viewers who lost access to RCTV punishing Chavez for closing RCTV at the ballot box. Our study, by contrast, does not use variation in cable penetration but instead exploits geographic variation in access to the Globovision signal. We argue that our finding, losing access to opposition TV leading to an increase in support for Chavez, can be explained by a different mechanism, switching to another opposition channel, Globovision. Given these two different mechanisms and the different sources of geographic variation, the two sets of findings are not inconsistent with one another, and we thus view the two studies as complementary in nature.

Finally, this paper is also related to a literature on media capture. Besley and Prat (2006) develop a model in which, even in the absence of state censorship, private media outlets might self censor negative information about the government in exchange for favorable policies. Media capture benefits governments by concealing potentially damaging information from the electorate, thereby increasing re-election rates. Such media capture is less likely under media pluralism, providing an additional motive for competition. Szeidl and Szucs (2017) empirically examine media capture in the context of Hungary, documenting that media outlets provide favorable coverage of the government in exchange for government advertising. In terms of incentives for favorable coverage in our context, the government provided sticks, revoking the broadcast license of RCTV, rather than carrots, in response to unfavorable coverage.

\section{Institutional Context}

This section provides background on the political situation in Venezuela, with a focus on the role of television in politics. We begin by describing Chavez's rise to power and the key elections during our sample period, followed by a discussion of the main television channels, including RCTV and Globovision, and the events surrounding the closing of RCTV in 2007.

\subsection{Political situation}

President Hugo Chavez was in office from 1999 until his death in 2013. In 1998, the leftist candidate won the presidential election, with 56 percent of the vote. Chavez promised a "Bolivarian revolution", designed to eliminate exclusion, poverty and government corruption. Since the beginning of Chavez's term, the right-wing opposition was committed to removing him from office ${ }^{4}$ In April 2002 the opposition led a coup, which failed after some initial successes. Later that year, in December 2002, the opposition

\footnotetext{
${ }^{4}$ The description of attempts to revoke President Chavez's mandate are extensively documented in Wilpert (2007), Corrales and Penfold (2011), and Nelson (2009).
} 
organized a strike in the oil industry, aimed at toppling Chavez, but, despite lasting three months, this too was ultimately unsuccessful. Two years later, in 2004, the opposition organized a recall referendum against Chavez.

During our sample period, there were a number of elections, and our empirical analysis of electoral returns focuses on five key elections during Chavez's term. In 2004, the right-wing coalition tried to remove Chavez from power via a presidential recall referendum, as mentioned above, but Chavez won with 59 percent voting against the recall $5^{5}$ Two years later, in the 2006 presidential election, Chavez was reelected to a second term, with 63 percent of the vote, against the right wing candidate Manuel Rosales. The following year, in December 2007, Chavez proposed to amend the Constitution via a referendum. These amendments included empowering the president to declare states of emergency for unlimited periods, extending Presidential terms from six years to seven years, and, perhaps most importantly, removing Presidential term limits, which restricted Presidents to just two terms in office..$^{6}$ Chavez lost this referendum, with only 49 percent of voters supporting these amendments designed to increase his powers. Another Constitutional referendum was held less than two years later, in February 2009, and Venezuelans did vote this time, with 54 percent supporting, to remove terms limits for the President and other key offices. This opened the door for Chavez to seek re-election for a third term in October 2012, and he won, with 54 percent of votes, against the right-leaning candidate Henrique Capriles. This election occurred during Chavez's illness, and he died just a few months later, in March 2013. He was replaced on an interim basis by his Vice President, Nicolas Maduro, who then won a disputed election in April 2013 and has served as President thereafter.

\subsection{Television in Venezuela}

Table 1 provides an overview of television channels in Venezuela. While the key public channel (VTV) tends to align itself with Chavez, the private television channels have tended to align their ideology with the opposition, especially at the start of Chavez's term, supporting the coup in 2002 and providing extensive coverage of anti-government protests during the oil strike later that year..$^{7}$ After these events, the tension between the private media and government was at its peak, and Chavez's stance became very aggressive, referring to the major private television channels (Venevision, RCTV, Globovision and Televen) as the

\footnotetext{
5 Chang-Tai et al. (2011) analyze the labor market implications of publicly supporting the recall campaign.

${ }^{6}$ See. https://elpais.com/internacional/2007/12/03/actualidad/1196636401_850215.html

${ }^{7}$ See Nelson (2009) and Dinneen (2012)
} 
"four Horsemen of the apocalypse". 8 In 2004, before the recall referendum, Chavez met with the owner of Venevision, which thereafter moderated their tone towards Chavez $?^{9}$ Then, Televen followed the initiative to moderate the anti-Chavez speech around the same period. 10

Following this, only two opposition channels remained. RCTV (Radio Caracas Television) is the oldest station, had the highest ratings, and had national broadcast coverage. In addition to its well-known antigovernment tone, RCTV was a major producer of entertainment programming, including soap operas and talk shows. ${ }^{11}$ Globovision is a news-only channel, providing nearly 20 hours of news per day (Table 1 but its broadcast signal was available in only two large metro areas, Caracas and Valencia. While Globovision content is available nationally via cable, penetration is relatively low during our sample period, and RCTV was the only opposition channel available via broadcast signal in the remainder of the country, outside of these two metro areas.

To summarize, there was a partitioning of television channels into opposition (RCTV and Globovision), moderate (Televen and Venevision), and pro-government (VTV). This is consistent with media monitoring during the 2006 Presidential elections. In particular, Figure 1, based upon data reported in EU-EOM (2006), documents that RCTV and Globovision devoted roughly two-thirds of their coverage to the opposition party and only one-third to Chavez. The tone of this coverage, not reported here, followed similar patterns, with decidedly positive coverage of the opposition and decidedly negative coverage of Chavez. The main public channel, VTV, by contrast, provided roughly 85 percent of their coverage to Chavez and only 15 percent to the opposition. This coverage of the opposition was negative, with coverage of Chavez disproportionately positive. The two moderate channels, Venevision and Televen, were also biased in favor of the government in terms of the share devoted to each party. In terms of tone, moderate channels tended to provide positive coverage of both parties. To summarize, media monitoring data strongly support the notion that there were only two opposition channels in Venezuela in 2006 and thus only one following the closing of RCTV in 2007.

\footnotetext{
${ }^{8}$ Reporters Without Borders $(2003)$ documents that Chavez accused the private channels of "inciting rebellion and disrespect for legitimate institutions and authorities", "broadcasting false, misleading or biased news reports", "harming the reputation and good name of persons or institutions" and promoting "subversion of public and social order."

9 http://www.nytimes.com/2007/07/05/world/americas/05venez.html?_r=1\&

${ }^{10}$ Wilpert (2007)

${ }^{11}$ While RCTV provided only four hours of news per day (Table 1, these programs had high ratings, as will be shown below.
} 


\subsection{The closing of RCTV}

The 20-year broadcast license for RCTV, which was granted on May 27, 1987, expired on May 27, 2007 and was not renewed by the government. Given this, the exact timing of the closing can be considered as exogenous. In terms of the process leading up to the closing of RCTV, the non-renewal was first announced five months prior, on December 28, 2006, and the decision was then upheld by the Supreme Court of Justice on April 17, 2007.12 The government's rationale for not renewing the license of RCTV had two key components: the alleged violations of broadcast laws and the participation in the coup and strike in the oil sector 13

RCTV was forced to stop broadcasting at midnight on May 27, 2007, and the channel was replaced overnight by TVES, a public channel. TVES inherited both the channel number of RCTV and its broadcast infrastructure. The government appointed a new President for TVES, Lil Rodríguez, with much of the staff of RCTV losing their positions overnight. ${ }^{14}$ RCTV did re-emerge on cable later that summer, under the name RCTV international, but was later, in early 2010, shut down again 15

The decision to take RCTV off the air was marked by significant public protests, and 70 percent of Venezuelans disapproved of the decision to not renew the license 16 As discussed above, Globovision was the only remaining broadcast channel aligned with the opposition but, unlike RCTV, which had a national broadcast infrastructure, the broadcast coverage of Globovision was limited to two metro areas. While Globovision was available nationwide via cable subscription, cable penetration was relatively low in Venezuela during our sample period, ranging from 17 percent in 2004, the start of our analysis, to 40 percent of households by 2011, the end of our analysis (Table 2). 17 Thus, broadcast was a more important delivery means than cable, although the gap between the two narrows towards the end of our sample period.

A key question is whether Globovision responded to the closing of RCTV by moderating their tone, and an implicit assumption in our analysis is that Globovision remained a key source of information to opposition voters. According to media monitoring of the 2012 Presidential Election, Capriles, the opposition candidate, received 64 percent of the Globovision coverage, which is nearly identical to the 65

\footnotetext{
${ }^{12}$ See https://en.wikipedia.org/wiki/RCTV.

13 Dinneen (2012)

${ }^{14}$ https://en.wikipedia.org/wiki/TVes (accessed July 11, 2019) and http://www.el-nacional.com/noticias/sociedad/rctv-anoscierre-amigo-para-siempre_241770 (accessed July 11, 2019).

${ }^{15}$ Wilpert (2007).

${ }^{16} \overline{\text { Wilpert }}($ 2007)

${ }^{17}$ Similarly, Weisbrot and Ruttenberg (2010) show that the audience share for cable is small, relative to broadcast TV, increasing from roughly 10 percent in 2004 to around one-third in 2010.
} 
percent share of coverage received by Rosales in the 2006 election, as documented in Figure $\left.\right|^{18}$ While Globovision was purchased by a pro-government investor in 2013, this occurred following the end of our sample period. Thus, this evidence suggests that Globovision remained in opposition to the government during our sample period.

To summarize, Venezuela has been characterized by a tense conflict between the government and the opposition, and this divide was also reflected in the media, with public channels aligned with the government and two key private channels, RCTV and Globovision, aligned with the opposition. Following the closing of RCTV and the opening of TVES, Globovisión became the only source of opposition television, and this was available via broadcast signal in only two metro areas. This left the majority of the territory without any opposition television and with only moderate and pro-government channels. We next examine the implications of this closing of RCTV for media consumption patterns, Chavez approval ratings, and voting returns.

\section{Changes in Viewership}

Using ratings data, we next examine viewership of news programming in Venezuela during the time period before and after the closing of RCTV. Our data are provided by Nielsen and measure ratings showby-show and day-by-day, covering the years 2006 and 2007. Ratings are also provided separately for four metro areas (Caracas, Valencia, Barquisimeto and Maracaibo) in Venezuela, and we compare two areas (Caracas and Valencia) with access to the Globovision broadcast signal to two areas without access to the signal (Barquisimeto and Maracaibo). In these data, shows are categorized according to their content, and, in some of our analyses, we compare ratings of news programming to ratings of non-news programming. Changes in the ratings of non-news programming, following the closing of RCTV, should be less affected by access to Globovision, which, as noted above, only provides news content. We also exploit the fact that ratings are provided separately for households with and without cable subscriptions. In particular, since Globovision is available via cable on a national basis, access to the Globovision broadcast signal should

\footnotetext{
${ }^{18}$ The 2012 monitoring was conducted by the Carter Center and the report is available at https://www.cartercenter.org/resources/pdfs/news/peace_publications/election_reports/venezuela-2012-election-studymission-final-rpt.pdf (accessed May 3, 2019).
} 
not matter in terms of viewership patterns for those households with cable subscriptions

\subsection{Viewership of News Programming}

We begin by examining how viewership of news programming on RCTV and then the replacement, TVES, evolves on a week-by-week basis during the period 2006-2007 and for households without cable subscriptions. Importantly, TVES took over the RCTV broadcast infrastructure, used the same channel number, and began broadcasting almost immediately following the closing of RCTV. Thus, to the extent that viewers are passive and do not respond to changes in ideological content, there might be no change in viewership patterns following the closing of RCTV.

As shown in Figure 2, by contrast, we find an immediate drop-off in viewership of news programming on TVES, relative to viewership of news programming on RCTV, following the closing of RCTV on May 27, 2007 and for households without cable subscriptions. In particular, viewership falls from roughly 5 to 10 percent prior to the closing of RCTV (i.e. to the left of the dashed line) to very low levels following the closing of RCTV (i.e. to the right of the dashed line) for these households without cable subscriptions. While viewership of RCTV news tended to be higher in the areas with access to the Globovision signal, the low viewership for TVES news is apparent in both types of areas following the closing of RCTV. This result is consistent with a preference for opposition news programming.

Given this finding of very low ratings for TVES, relative to RCTV, we next examine whether these viewers switched from RCTV/TVES to other channels aligned with the opposition. For households without cable, this involved Globovision and, as noted above, this type of switching was only available in areas with access to the Globovision signal. As shown in Figure 3, there was indeed a sharp increase in viewership of Globovision following the closing of RCTV for these households without cable subscriptions and with access to the Globovision signal. Some of this increase is temporary, with a large increase in viewership during the weeks immediately following the closing of RCTV. Note that this temporary increase may reflect viewer interest in Globovision coverage of protests associated with the closing of RCTV. Even following the protests, in the later weeks of 2007, however, there is a noticeable increase in viewership of Globovision, relative to the period prior to the closing of RCTV.

We next examine whether this switching to Globovision in areas with access to the broadcast signal translates into higher viewership of news programming in general, aggregated across all channels. As shown in Figure 4, viewership of news programming tends to be higher in areas with the Globovision signal even before the closing of RCTV, relative to areas without the Globovision signal, for these households without cable subscriptions. Even so, there does appear to be a widening of the gap following the closing 
of RCTV, reflecting the switching by these households in areas with access to the Globovision signal from RCTV to Globovision. While some of this is temporary and the series is noisy in general, there does appear to be a larger gap in general after the closing of RCTV, when compared to the time period prior to the closing of RCTV. This result is again consistent with a preference for opposition television.

\subsection{Magnitudes}

To quantify these results, we first calculate switching rates. That is, we measure the fraction of the reduction in the consumption of opposition news on RCTV that was offset by the increased consumption of opposition news on Globovision in areas with access to the broadcast signal. An exclusive focus on ratings suggests relatively low switching rates: as shown Panel A of Table 3 , the viewership of opposition news on RCTV in areas with access to the Globovision fell from 8.91 percent of households to 0 percent following the closing of RCTV, and viewership of Globovision news rose from 1.30 percent to only 2.25 percent. ${ }^{19}$ But, as noted above, Globovision offers 19.57 hours of news per day, compared to 4.10 hours on RCTV. Thus, weekly viewership of news on RCTV fell by 153 minutes per household, while daily viewership of news on Globovision rose by 78 minutes. Thus, overall consumption of opposition news fell by 75 minutes per week. As summarized in Panel B of Table 3, this implies an economically significant switching rate of 51 percent, meaning that roughly one-half of the reduction in viewership of news on RCTV was offset by increased viewership of Globovision where available.

While these measures of switching rates focus on Globovision areas, the subsequent analysis of support for Chavez is based upon comparisons of areas with and without the Globovision signal. Indeed, key to our empirical strategy is the idea that, as a result of switching, consumption of opposition news fell less in areas with the Globovision signal, relative to areas without the signal. To address this issue, we next measure the drop in consumption of opposition news in non-Globovision areas. As shown in Panels C and D of Table 3, viewership of opposition news in non-Globovision areas fell by 102 minutes. Thus, viewership of opposition news in areas with access to the Globovision signal (75 minutes) fell less, representing a relative increase in viewership of opposition news of 27 minutes.

\subsection{Viewership of non-news Programming}

For comparison purposes, we next examine changes in the ratings of non-news programming. These ratings, following the closing of RCTV, should be less affected by access to Globovision, which is news

\footnotetext{
${ }^{19}$ These are average ratings in Globovision areas before and after the closing of RCTV in Figures 2 and 3
} 
only. As shown in Figure 5, there was a sharp reduction in viewership of non-news programming across all areas following the closing of RCTV. This sharp reduction in viewership of non-news is likely driven by the loss of popular entertainment programming on RCTV and the associated lack of interest in the entertainment programming offered by TVES. More importantly, the viewership patterns for non-news, both before and after the closing of RCTV, are similar for both areas with and without access to the Globovision signal. Thus, the relative decrease in consumption of news in areas without access to the Globovision signal cannot be solely explained by general trends in television viewership across both news and non-news programming in these areas.

\subsection{The Role of Cable}

We next compare these trends in viewership for households with and without cable subscriptions. Since Globovision is available in all areas via cable subscriptions, we should expect a similar pattern of switching regardless of whether or not the area has access to the Globovision broadcast signal. As shown in Figure 6, there is again an immediate drop-off in viewership on RCTV/TVES following the closing of RCTV and the opening of TVES on May 27. Moreover, the patterns, for areas without and without access to the Globovision signal, are quite similar to that for households without cable (Figure 2). We next analyze viewership of Globovision programming for these households with cable, comparing areas with and without access to the Globovision signal. As shown in Figure 7, there is again a sharp increase in viewership of Globovision following the closing of RCTV, and these patterns are present in both areas with and without access to the Globovision signal. In terms of overall news viewership for these households with cable subscriptions, there do not appear to be systematic differences between areas with and without access to the Globovision signal (Figure 8). This is in contrast to the widening gap between areas with and without access to the Globovision signal for households without cable (Figure 3). Finally, for comparison with Figure 5, we examine trends in viewership of non-news programming for households with cable. As shown in Figure 9, we again find a reduction of viewership of non-news for households with cable

following the closing of RCTV, a trend that is apparent for both areas with and without access to the Globovision signal.

Taken together, the fact that viewership trends for these households with cable access is similar across areas with and without access to the Globovision signal suggests that our baseline results are not driven by other factors that may have changed in these areas. Instead, it is consistent with our interpretation that access to the Globovision signal led to changes in viewership patterns for households without cable 
following the closing of RCTV.

\subsection{Summary}

We find sharp changes in viewership patterns following the government closing of RCTV and the corresponding change in station ideology. In particular, viewers quickly moved away from TVES, and we also document a corresponding increase in viewership of Globovision for households either with access to the station via broadcast signal or via a cable subscription. This leads to differences in both the ideological bundle consumed by viewers and in exposure to news overall. In the remainder of the paper, we examine whether these changes in news consumption patterns affect approval ratings for Chavez in survey data and, ultimately, his electoral performance at the ballot box.

\section{Chavez Approval Ratings}

Using survey data, we next examine trends in evaluations of Chavez, before and after the closing of RCTV in May 2007 and accounting for the Globovision broadcast signal. To do so, we examine annual survey data 2005-2011 from Latin Barometer. These surveys occur towards the end of the calendar year and we thus have two years (2005 and 2006) of surveys prior to the closing of RCTV in May 2007 and five years of surveys after the closing of RCTV (2007-2011). In these data, respondents evaluate Chavez on a 1 to 10 scale (with 1 representing very bad and 10 representing very good).

We also use these survey data to examine other outcomes that might be affected by access to the Globovision signal. These survey questions include queries regarding general ideology (on a left-to-right scale, with increases associated with movements towards the right) and overall support for the Venezuelan government. In addition, given that foreign relations were a key component of government propaganda, we examine whether access to opposition television via the Globovision signal change support for foreign leaders. In particular, we examine whether access to Globovision increases support for key allies of Chavez, such as Fidel Castro of Cuba, and reduces support for his foreign enemies, such as the rightleaning Presidents of Colombia (Alvaro Uribe until 2010 and then Juan Manuel Santos) and the Presidents 
of the USA during the sample period (George W. Bush until 2008 and then Barack Obama).

\subsection{Globovision signal}

To measure access to the Globovision signal, we use both information on the municipality of residence for each respondent in the Latin Barometer and information on the broadcast towers for Globovision. Regarding the latter, we requested and received information from Globovision on the location (latitude and longitude) of their four towers, three of which are located in the Caracas metro area and one of which is located in the Valencia metro area. In addition, we received information on the power and height of each tower. To measure access to the Globovision signal, we use the Irregular Terrain Model, which uses information on the source of the signal and the terrain to predict the strength of the signal at destination locations. ${ }^{20}$ Using information on these four towers, we measure the signal (categorized as no signal, a weak signal, or a strong signal) for geographic grid cells. These measures are then aggregated from grid cells to the municipality level, and we use two such aggregates. First, we develop a dummy variable, which we refer to as Globovision city, indicating whether or not a majority of the grid cells in the municipality receives the signal. Second, we use a continuous measure based upon the fraction of grid cells in the municipality that receive the signal.

Figure 10, which focuses on the heavily populated northern part of the country, depicts the results from this model, where the weak signal is depicted in yellow and the strong signal is depicted in green. As shown, the signals are indeed concentrated in the Valencia and Caracas metro areas. Moreover, their reach depends upon the terrain, with the signal traveling long distances over, for example, the water but much shorter distances over the hilly terrain in this part of Venezuela. In total, we predict the presence of a signal in at least one grid cell for 68 out of 335 municipalities, with only 16 meeting our definition (majority of the municipality receiving the signal) as a Globovision city.

We next use this variation across municipalities to examine changes in support for Chavez following the closing of RCTV. To be clear, we do not claim that signal access is randomly assigned, and, as noted above, the signal is concentrated in the densely populated part of the country. Instead, we also use variation induced by the closing of RCTV, the timing of which can be considered as exogenous given the 20-year license. Given this, our key identifying assumption is that trends in support for Chavez in Globovision municipalities would have followed trends in support for Chavez in non-Globovision municipalities in the absence of the closing of RCTV. We address this identifying assumption and possible threats to this

\footnotetext{
${ }^{20}$ In particular, we use the radio coverage tool on the website http://www.nautel.com/.
} 
assumption after presenting our baseline results.

\subsection{Baseline Results}

We begin with an analysis of Chavez approval ratings. As shown in Figure 11, there was a reduction in support for Chavez in general over the sample period. For example, in 2005 and 2006, over 40 percent of respondents gave Chavez the highest possible approval score (10 on the 1 to 10 scale), whereas during the period 2007 to 2011, the proportion giving Chavez the highest score never exceeded 30 percent. There is some evidence of a corresponding increase in the lowest possible approval score ( 1 on the 1 to 10 scale), exceeding 25 percent in 2008, but these proportions are noisy and return to baseline levels by the end of the sample period.

Building upon these general results, we next examine trends according to access to the Globovision signal. In particular, based upon the research design described above, Figure 12 provides information on the distribution of Chavez approval ratings, separately for municipalities with and without access to the Globovision signal and then also separately before and after the closing of RCTV. As shown, respondents in both types of municipalities expressed considerable support for Chavez in 2005 and 2006, with over 40 percent giving Chavez the highest possible score of 10 in municipalities without the Globovision signal and a higher proportion, over 50 percent, in the corresponding set of municipalities with access to the signal. These both drop considerably, to just over 20 percent in municipalities with the Globovision signal and roughly 25 percent in municipalities without the Globovision signal, in the period after the closing of RCTV in 2007. Thus, the decline in support for Chavez was sharper in areas with access to the Globovision broadcast signal. There appears to be a corresponding increase in the lowest possible score (very bad) in municipalities with access to the Globovision signal, relative to those municipalities without access to the signal. But, in general, the relative reduction in top scores in municipalities with access to the Globovision signal is offset by increases throughout the distribution of approval ratings. To summarize, we find that the drop in support for Chavez during the sample period was strongest in the areas with access to opposition television via the Globovision signal.

To investigate these patterns more rigorously, we next estimate an ordered logit model, which accounts for the ordinal nature of approval ratings. In particular, using the information on approval ratings and the strength of the Globovision signal, we specify the following index of support for Chavez:

$$
\text { support }=\beta_{1} \text { After }_{t}+\beta_{2} \text { Signal }_{m} x \text { After } r_{t}+\alpha_{m}
$$


In this equation, the municipality fixed effects $\left(\alpha_{m}\right)$ capture time-invariant differences between places with and without access to the Globovision signal, and the parameter $\beta_{1}$ captures changes in approval for Chavez following the closing of RCTV in May 2007. After accounting for these time-invariant differences across cites and any changes in nationwide support for Chavez following the closing of RCTV, the key parameter of interest, $\beta_{2}$, captures trends in the municipalities that receive the Globovision signal, relative to trends in those municipalities that do not receive the Globovision signal. To account for the panel structure of these data, standard errors are clustered at the municipality level.

Results from this regression are reported in column 1 of Table 4. As shown, we do find a drop in support for Chavez in both types of municipalities following the closing of RCTV, as reflected by the negative coefficient in the first row. But the decline in sharper in those municipalities that retained access to opposition television via the Globovision signal, as reflected in the negative coefficient on the interaction in the second row, and this effect is statistically significant at conventional levels. Thus, we find that, in municipalities with access to the Globovision signal, the switching from RCTV to Globovision, as documented above, appears to be associated with a reduction in support for Chavez following the closing of RCTV in May 2007.

\subsection{Threats to Identification}

As noted above, our key identifying assumption is that trends in support for Chavez in Globovision municipalities would have followed trends in support for Chavez in non-Globovision municipalities in the absence of the closing of RCTV. Given that the 20-year license was granted in 1987, the exact timing of the expiration is arguably exogenous. Yet, if support for Chavez was already falling in Globovision municipalities in a differential manner for other reasons, then our interaction coefficient will overstate the role of access to Globovision in support for Chavez.

We address this concern in four ways. The first involves accounting for observable differences between areas that receive the Globovision signal and other areas. For example, the Caracas and Valencia metro areas, where the signal is concentrated, are clustered in the more densely population northern part of the country. If any negative perceptions of the government spread more rapidly in urban areas, then we might expect a differential drop in support for Chavez in these Globovision municipalities during out sample period. To address this point, we next include observable controls (urban, gender, age, and socioeconomic status) and, as shown in column 2, of Table 4 , the differential decline in approval of Chavez in municipalities with access to the Globovision signal is robust to these controls. More importantly, in 
column 3, we allow for the coefficients on these controls to change following the closing of RCTV, relative to the period prior to the closing of RCTV. This allows, for example, support for Chavez to fall more quickly in urban areas and thus compares the differential decline in support between urban areas with and without access to Globovision. Again, our results are robust to these more general controls.

Our second strategy towards addressing these threats to identification involves developing a more narrow comparison group, which, in our baseline specification, includes all municipalities in Venezuela that do not receive the Globovision signal. In particular, we focus the comparison group on those states that either include Globovision municipalities or border these Globovision states ${ }^{21}$ Taken together, these ten states account for less than 20 percent of the area of the country and are comparable in nature, located in the densely populated northern central region of the country. As shown in column 4 of Table 4 , the results based upon this narrow geographic control group are similar in nature, with a statistically significant decline in support for Chavez in Globovision municipalities, relative to this narrow comparison group, following the closing of RCTV. Thus, our baseline results are robust to a more narrow comparison group.

Our third strategy towards addressing these threats to identification involves estimating placebo timing specifications. This allows us to examine whether the changes in support for Chavez in Globo municipalities, relative to control municipalities, occurred in the year that RCTV closed or in other years surrounding this event. More specifically, we measure $A F T E R_{t}$ using alternative definitions before and after the actual closing of RCTV. That is, we estimate specifications in which RCTV is assumed to have closed in years other than the actual year of 2007 (i.e. 2006, 2008, 2009, 2010, and 2011). As shown in Table 5, our baseline specification (column 2) has the largest coefficient on the key interaction term, when compared to specifications that allow for changes in Globovision one year before the actual closing and one to four years after the closing. Moreover, only the specification that uses the following year as the change has an interaction coefficient that is statistically significant. Related to this, following a literature on structural breaks, we can locate the single break that best fits the data. As shown in the final row, the baseline specification has the best fit, in terms of maximizing the log likelihood ${ }^{22}$ To summarize, while we cannot definitely rule out the role of changing unobserved factors in Globovision municipalities following the closing of RCTV, these results suggest that any such changes would likely have occurred in exactly the same year as the closing of RCTV. This allows us to rule out changes in other years surrounding the closing of RCTV as drivers of our baseline results and thus yields credence to our interpretation related to

\footnotetext{
${ }^{21}$ These states are Yaracuy, Carabobo, Cojedes, Guarico, Anzoategui, Aragua, Vargas, Distrito Federal, Miranda, and Falcon.

${ }^{22}$ While national reductions in support for Chavez following 2006 may have contributed to this improved fit, the t-statistic on the interaction coefficient is also largest in the baseline specification.
} 
the closing of RCTV in 2007.

Fourth, we address a specific concern related to internet access and internet use. If the internet expanded more rapidly in more urban areas, those with the Globovision signal, during our sample period, this would be a key threat to identification, with increased internet use following the closing of RCTV, rather than access to Globovision, explaining our key results. Based upon a survey question in the our survey data, we do find substantially higher internet use in the years 2007-2011, those following the closing of RCTV, relative to the survey years 2005 and 2006, those prior to the closing of RCTV. Across all municipalities, internet use rose from 34.4 percent to 53.2 percent. Yet this increased occurred in both Globovision and non-Globovision municipalities, and we do not find significant differences in the increase between Globovision and non-Globovision municipalities ${ }^{23}$ In addition, we have also estimated specifications that include these measures of internet use in the set of control variables, and our results are virtually unchanged ${ }^{24}$

\subsection{Additional Specifications}

As a robustness check on our measure of Globo city, we use a continuous measure of signal intensity (the fraction of the municipality receiving the signal) rather than our baseline discrete measure (whether or not a majority of the municipality receives the signal). As shown in column 5 of Table 4 , our results are robust to this alternative measure. Along these lines, we present results in column 6 in which we use an indicator for whether or not a majority of the municipality receives a strong signal (our baseline measure uses a weaker signal measure). As shown, our results are again very similar to the baseline. Taken together, our baseline results are robust to demographic controls and alternative measures of the strength of the Globovision signal.

To further investigate the timing of our results, we next estimate event study ordered logit model specifications, in which we allow the difference between signal and no-signal municipalities to vary over time in a flexible way:

$$
\text { support }=\beta_{t} \text { Signal }_{m}+\alpha_{m}+\mu_{t}
$$

where $\mu_{t}$ is now a series of year fixed effects and $\beta_{2006}$ is normalized to zero.

As shown in Figure 13, there are not significant differences in support for Chavez between municipal-

\footnotetext{
${ }^{23}$ Internet use increased from 41.0 percent to 63.0 percent in Globovision municipalities and from 32.9 percent to 50.3 percent in non-Globovision municipalities. The differences in the growth of internet use between Globovision municipalities and other municipalities are not statistically significant.

${ }^{24}$ These results are available upon request from the authors.
} 
ities with and without access to the Globovision signal in 2005, relative to 2006. Following the closing of RCTV, by contrast, access to the Globovision signal is associated with a drop in support for Chavez in 2007, relative to 2006, and this drop becomes even sharper in 2008. Following this, there is a slow rebound starting in 2009 and continuing until the end of the sample period. All of these five post-RCTV coefficients on access to the Globovision signal are negative, and four out of five, all except the final year 2011, are statistically different from zero at conventional levels.

\subsection{Other Impacts of Censorship}

To provide readers with a sense of the broader impact, above and beyond support for Chavez, of access to opposition television, we next examine responses to other questions related to Venezuelan politics in these Latinbarometer survey data. In particular, we examine whether access to opposition television via the Globovision signal following the closing of RCTV shifts ideology to the right, reduces approval of the Venezuelan government, increases support for allies of Chavez, and reduces support for his enemies. As shown in Table 6, we do find general support for these hypotheses, although three out of the five results are not statistically significant at conventional levels. In particular, access to the Globovision signal is associated with a movement to the right in the ideological spectrum (column 1) following the closing of RCTV (although this result is not statistically significant). Likewise, there appears to be reduction in support for the government (column 2) in municipalities with access to the Globovision signal and following the closing of RCTV (although this result is also not statistically significant). Turning to other leaders, we document a statistically significant reduction in support for Fidel Castro, a key foreign ally of Chavez, following the closing of RCTV in municipalities with access to Globovision signal. Likewise, we find a corresponding increase in support for key enemies, including Uribe and Santos, Presidents of Colombia (column 4), and Bush and Obama, Presidents of the USA (column 5), in municipalities with access to the Globovision signal following the closing of RCTV.

\subsection{Summary}

We find that access to the Globovision signal is associated with a reduction in support for Chavez following the closing of RCTV. These results are robust to the inclusion of observable controls and to restricting our analysis to a narrow comparison group. Moreover, we show in placebo specifications that the drop in 
support for Chavez in Globovision municipalities was more pronounced in 2007, the year in which RCTV was closed. In event studies, we find that the effect intensifies over time before rebounding back to levels close to baseline support by the end of the sample period. We also find some evidence that access to the Globovision signal is associated with a reduction in support for foreign allies and an increase in support for foreign enemies.

\section{Electoral Results}

To examine whether these changes in survey-based approval ratings translate into changes in support for Chavez at the ballot box, we next use data on electoral returns from municipalities for key elections in Venezuela during the period before and after the closing of RCTV in May 2007. In particular, we examine the following five key elections, which were discussed in more detail in Section 3:

1. 2004 Presidential Recall Referendum (before RCTV closing)

2. 2006 Presidential Election (before RCTV closing)

3. 2007 Constitutional Referendum (after RCTV closing)

4. 2009 Constitutional Referendum (after RCTV closing)

5. 2012 Presidential Election (after RCTV closing)

For each election, we translate voting returns into a measure of the fraction of the electorate supporting Chavez, relative to the opposition. For the 2006 and 2012 Presidential elections, we do so in the natural way, by measuring the vote share for Chavez relative to the opposition candidate (Manuel Rosales in 2006 and Henrique Capriles in 2012). For the 2004 recall referendum, we measure support for Chavez as the fraction of the electorate voting against the effort to recall Chavez. For the two constitutional referenda, we measure support for Chavez based upon the fraction of the electorate in each municipality that supported the referendum. This measure is natural given that both referenda were proposed by Chavez and were broadly interpreted as an attempt to consolidate political power in the office of the Presidency.

\subsection{Baseline Results}

Figure 14 plots the vote share for Chavez in log odds form (i.e., the natural log of the ratio of vote 
share for Chavez to the vote share against Chavez). In municipalities without access to the Globovision signal, voters were 66 percent more likely to support Chavez, relative to the opposition, before the closing of RCTV, and 44 percent more likely to do so after the closing of RCTV. Likewise, in municipalities receiving the Globovision signal, voters were 30 percent more likely to vote for Chavez, relative to the opposition, before the closing of RCTV, but slightly less likely (negative log odds) after the closing of RCTV. Comparing the two declines, there is a 23 percentage point reduction in the areas without the Globovision signal but a larger reduction, 33 percentage points, in the areas with the Globovision signal. Thus, consistent with the results using survey-based approval ratings, we find a disproportionate decline in electoral support for Chavez in areas with access to opposition television via the Globovision signal after the closing of RCTV in 2007.

To test for the statistical significance of these changes, we next report results from the following regression:

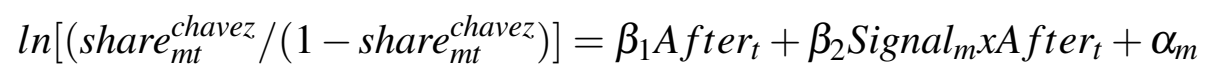

where, as before, the municipality fixed effects $\left(\alpha_{m}\right)$ capture time-invariant differences between municipalities with and without access to the Globovision signal, and the parameter $\beta_{1}$ captures nationwide changes in electoral support for Chavez at the polling booths following the closing of RCTV in 2007. After accounting for these time-invariant differences across municipalities and national trends in support for Chavez, the key parameter of interest, $\beta_{2}$, captures changes in voting in municipalities that receive the Globovision signal, relative to municipalities that do not receive the Globovision signal, following the closing of RCTV in 2007. To account for the panel nature of the analysis, standard errors are again clustered at the municipality level.

As shown in column 1 of Table 7, we again find a general decline in support for Chavez following the closing of RCTV in 2007. But, more importantly, this effect is particularly pronounced in municipalities that retained access to opposition television via the Globovision signal, and both of these differences are again statistically significant at conventional levels. These findings suggest that access to Globovision following the closing of RCTV, and viewers switching towards this channel, contributed towards a decline 
in support for Chavez at the voting booth.

\subsection{Threats to Identification}

In parallel to addressing threats to identification in our analysis of approval ratings data, we begin by defining a narrow comparison group, consisting of only states with Globo cites and bordering states. This group is more comparable in nature to Globo municipalities as it focuses on the densely populated northern central part of the country. As shown in column 2, our results are robust to this narrow control group, with significant declines in electoral support for Chavez in Globo municipalities, relative to nearby municipalities.

We next estimate placebo timing specifications using voting returns data. That is, we estimate specifications in which RCTV is assumed to have closed in years other than the actual year of 2007. In this case, those years include 2006, 2009, and 2012. As shown in Table 8, the results for our baseline specification (column 2) are very similar to those using 2009 as the event date. Using 2006 or 2012 as the event date, however, yields interaction coefficients that are close to zero and statistically insignificant. Moreover, as shown in the final row, the baseline specification has the best fit, as measured by the R-squared in this case. These results again suggest that any changes in support for Chavez unrelated to the closing of RCTV in these areas would have also occurred in 2007, yielding credence to our identification strategy.

\subsection{Additional Specifications}

To measure the magnitude of the electoral effects, and to show that it does not depend upon the log-odds formulation, we next consider a similar specification but with the Chavez vote share, rather than the log odds formulation, as the dependent variable. As shown in column 3 of Table 7, there is a roughly 5 percentage point decline in the vote share for Chavez in municipalities without access to the Globovision signal following the closing of RCTV but a 7 percentage point decline in the Chavez vote share in municipalities with access to the Globovision signal. Thus, the differential decline equals 2 percentage points, and this decline is statistically significant at conventional levels.

To examine the robustness of our measure of Globo city, we next return to our baseline measure of $\log$ odds but consider a continuous measure of the signal, the fraction of the grid cells in the municipality with access to the Globovision signal. As shown in column 4, we again find a strong reduction in electoral support for Chavez in municipalities with access to opposition television following the closing of RCTV. Finally, in column 5, we document that our results are robust to using a measure of the signal based upon the more stringent measure of signal strength. To summarize, our results using electoral returns data 
are robust to alternative measures of support for Chavez and alternative measures of the strength of the Globovision signal.

To further investigate the dynamics of our results using voting data, we next estimate event study specifications by allowing the key coefficient on access to the Globovision signal to vary over time in the following regression:

$$
\ln \left[\left(\operatorname{share}_{m t}^{\text {chavez }} /\left(1-\operatorname{share}_{m t}^{\text {chavez }}\right)\right]=\beta_{t} \text { Signal }_{m}+\alpha_{m}+\mu_{t}\right.
$$

where $\beta_{2006}$ is again normalized to zero and $\alpha_{m}$ and $\mu_{t}$ capture, respectively, municipality and time fixed effects. As shown in Figure 15, we find that the effect of having access to the Globovision signal first appears in 2007 (held December 2, roughly five months following the closing of RCTV), and the effect becomes stronger in 2009, followed by a rebound back to 2007 levels during the 2012 elections. This pattern of effects is similar to that in Figure 13, which documented that the effect on approval for Chavez associated with access to the Globovision signal was strongest during the survey interviews held in 2008 and 2009 before rebounding back to baseline levels towards the end of the sample period.

\subsection{Turnout}

In addition to analyzing vote shares, we also study participation in elections (i.e., turnout). Given that we do not have annual data on the number of eligible voters and thus cannot measure turnout rates directly, we instead measure participation via the $\log$ of the number of votes cast. Thus, our key coefficient on the interaction between the post-RCTV indicator and an indicator for access to the Globovision signal can be interpreted as the percent change in turnout following the closing of RCTV in municipalities with access to the Globovision signal, relative to the change in turnout in municipalities without access to the Globovision signal.25

As shown Table 9, we find that turnout rose roughly 4 percent following the closing of RCTV in municipalities without access to the Globovision signal but 8 percent in municipalities with access to the Globovision signal, a statistically significant differential increase in turnout of 4 percentage points. We find similar results with a narrow control group, which focuses on states with Globo municipalities and bordering states (column 2). Our baseline result is robust to using a continuous measure of signal intensity

\footnotetext{
${ }^{25}$ In particular, note that the $\log$ turnout rate can be written as $\ln ($ votes $/$ eliglble $)=\ln ($ votes $)-\ln ($ eligible $)$. Since we do not have information on the number of eligible voters on a year-by-year basis, we instead incorporate ln(eligible) into the municipality fixed effects.
} 
(column 3) and also to the more stringent measure from using the high signal strength threshold (column 4). Finally, we consider the timing of these effects with respect to turnout in Figure 16. Here the pattern is a bit different, relative to the pattern in the previous event studies, with an immediate and large increase (15 percent) in turnout during 2007 in municipalities with access to Globovision, relative to municipalities without Globovision. We again find that the effects diminish over time, and there are no essentially no differences in turnout between municipalities with and without access to the Globovision signal by 2012, the end of the sample period.

\subsection{Magnitudes and Counterfactuals}

Combining the results from the media consumption analysis with the results from the voting analysis, we next measure the quantify our results. Recall from above that consumption of opposition news rose by 27 minutes per week and per household in areas with access to the Globovision signal, relative to areas with access to the signal. Likewise, the vote share for Chavez fell by 1.87 percentage points in areas with access to the Globovision signal, relative to areas with access to the signal. This implies that an additional weekly minute of opposition news reduces support for Chavez by 0.07 percentage points. By comparison, Martin and Yurukoglu (2017) conclude that a 3-minute increase of weekly viewership of Fox News (MSNBC) increases voting for Republicans among centrists by 0.65 (-0.04) percentage points, when averaged across years. Thus, our corresponding 3-minute magnitude of 0.21 percentage points is stronger than the MSNBC effect but weaker than the Fox News effect.

Combining the media consumption analysis with the Chavez approval analysis also allows us to conduct counterfactuals. In particular, we next conduct counterfactual exercises designed to investigate the link between media consumption and persuasion. These include a no-switching counterfactual (i.e. a switching rate of zero) and a counterfactual with a switching rate of 100 percent, when compared to our measured switching rate of 51 percent. In addition, we conduct a counterfactual in which Chavez closes both RCTV and Globovision.

Figure 17 summarizes the results from these counterfactual experiments. Our baseline difference-indifference estimate implies that the vote share for Chavez fell by 1.83 percentage points in areas with access to Globovision following the closing of RCTV. Under a counterfactual in which RCTV did not close, there is no differential change is the Chavez vote share, by assumption. Had RCTV closed but viewers did not switch to Globovision in areas with access (i.e., a switching rate of zero), we predict that 
viewership of opposition news would have fallen more, by 52 minutes per week per household, in areas with access to the Globovision signal, reflecting the fact that viewership of RCTV was higher in areas with the Globovision signal. Given this, we predict that the Chavez vote share would have actually risen by 3.58 percentage points. Comparing this to our baseline estimates, this implies that viewer responses, in the form of switching to non-censored outlets, reduced the Chavez vote share by a substantial 5.41 percentage points. At the other extreme, had RCTV closed and all RCTV viewers switched to Globovision in areas with access (i.e,, a switching rate of one), we predict that viewership of opposition television would have risen by 102 minutes per household per week in areas with access to the Globovision signal, relative to areas without. Given this, the Chavez vote share would have fallen by an economically significant 7.05 percentage points. Finally, had both RCTV and Globovision closed, we predict that viewership of opposition news in areas with the Globovision signal would have fallen by 159 minutes per week per household, relative to areas without the signal. Given this, the Chavez vote share would have increased by 11 percentage points in areas with the signal, relative to areas without. This large increase, relative to our baseline decline of 1.83 percentage points, reflects three mechanisms: RCTV viewers can no longer switch to Globovision, existing Globovision viewers also lose access to opposition television, and viewership of RCTV was also higher in areas with the Globovision signal. Thus, censorship is less effective in an environment where opposition outlets remain available, and, conversely, censorship is more effective when implemented in a comprehensive manner, via targeting all opposition outlets.

\subsection{Summary}

We find that access to opposition television via the Globovision signal is associated with a significant reduction in support for Chavez at the polling booth following the closing of RCTV in May 2007. This effect intensifies in the years following the closing of RCTV before rebounding back. We also find evidence that access to opposition television via the Globovision signal increased voter turnout following the closing of RCTV. Taken together, these patterns are consistent with the results in the prior sections, which documented that viewership of Globovision increased following the closing of RCTV and that approval ratings in survey data fell accordingly. Using these estimates, we calculate electoral support for Chavez under counterfactual media consumption scenarios, suggesting that viewers switching to non-censored 
outlets in response to censorship led to significant reductions in support for incumbents.

\section{Theoretical Explanation}

In this section, we develop a simple economic model that is consistent with our three key empirical results: 1) voters switch to Globovision, when available, following the closing of RCTV, 2) the closing of RCTV increased support for the government in areas that lost access to opposition television, relative to places that retained access to opposition television via Globovision, and 3) the differences in support for government between places with and without access to opposition television, via the Globovision signal, fade over time, following the closing of RCTV. We present the baseline model followed by five extensions.

\subsection{Baseline Model}

We consider an economic model in which media outlets issue informative reports but in which the government might censor reports that reflect negatively upon their performance. There are two states of the world, good $(s=g)$ and bad $(s=b)$. The state reflects the performance of the incumbent government and could be interpreted, for example, as the state of the economy or the degree of corruption in government. The probability of the bad state equals $\pi_{b}$. A media outlet receives a signal $(\sigma)$ containing no information about the state of the world $(\sigma=\phi)$ with probability $p$, and, with probability $1-p$, receives a signal that reveals the true state $(\sigma=s)$. Based upon this information, the media outlet then issues a report $(r)$, which reflects either their signal $(r=\sigma)$ or no information $(r=\phi)$. Thus, media outlets cannot issue a good report when the state is bad and vice-versa.

While media outlets would like to issue a report when they have relevant information, the government may censor reports when the signal is bad. ${ }^{26}$ While the censorship environment is determined exogenously in the baseline model, we later consider an extension in which the incumbent government chooses the degree of censorship. In particular, we assume here that there are two media environments, uncensored $(m=u)$ and censored $(m=c)$. In the former case, there is no censoring of bad signals. In the latter environment, which occurs with probability $\pi_{c}$, the government censors bad signals with probability $q$, and, in this case, the report contains no information $(r=\phi)$. Thus, when the media does not issue a report, this could reflect either censoring or a lack of information available to the media outlet. To summarize, in the censored environment, the media outlet issues a bad report with probability $(1-p) \pi_{b}(1-q)$, issues a good report with probability $(1-p)\left(1-\pi_{b}\right)$, and issues no report with probability $p+(1-p) \pi_{b} q$.

\footnotetext{
${ }^{26} \mathrm{We}$ later consider an extension in which opposition media might also engage is censorship by suppressing signals revealing that the state is good.
} 
While voters are assumed to know all relevant probabilities $\left(\pi_{b}, \pi_{c}, p, q\right)$, we assume for now that they do not observe the media environment and can only learn about the environment from contemporaneous media reports. We later relax this assumption in two ways, one involving voters learning about the media environment from past media reports and another involving voters receiving independent and informative signals regarding the media environment.

Given this set up, citizens observing an informative report $(r=b$ or $r=g$ ) learn the true state. Upon receiving no report $(r=\phi)$, by contrast, voters do not know whether the government censored a bad report or the media received no signal ${ }^{27}$ In this case, voters follow Bayes rule and update as follows:

$$
\operatorname{Pr}(s=b \mid r=\phi)=\frac{\operatorname{Pr}(r=\phi \mid s=b) \operatorname{Pr}(s=b)}{\operatorname{Pr}(r=\phi \mid s=b) \operatorname{Pr}(s=b)+\operatorname{Pr}(r=\phi \mid s=g) \operatorname{Pr}(s=g)}
$$

Since the government does not censor favorable reports, the probability that the media outlet issues no report when the state is good equals the probability that the outlet received no information. That is, $\operatorname{Pr}(r=\phi \mid s=g)=p$. When the state is bad, by contrast, it is possible that the report is censored and thus $\operatorname{Pr}(r=\phi \mid s=b)=p+(1-p) \pi_{c} q$. Using the fact that $\operatorname{Pr}(s=b)=\pi_{b}$ and substituting back in, we have that:

$$
\operatorname{Pr}(s=b \mid r=\phi)=\frac{\left[p+(1-p) \pi_{c} q\right] \pi_{b}}{\left[p+(1-p) \pi_{c} q\right] \pi_{b}+p\left(1-\pi_{b}\right)}
$$

In the absence of censoring $\left(\pi_{c}=0\right.$ or $\left.q=0\right)$, we have that $\operatorname{Pr}(s=b \mid r=\phi)=\pi_{b}$, meaning that voters do not update in either direction in the absence of a media report. With censoring $\left(\pi_{c}>0\right.$ and $\left.q>0\right)$, by contrast, voters understand that it is possible that the government censored the report and, when faced with no media reports, thus infer that the bad state is now more likely. That is, $\operatorname{Pr}(s=b \mid r=\phi)>\pi_{b}$. More generally, one can show that the ex-post belief of a bad state following no report is increasing in the degree of censoring (i.e. in both $\pi_{c}$ and $q$ ).

Is censoring an effective government strategy? That is, does censorship systematically decrease the likelihood that voters believe the state is bad? To investigate this issue, consider the probability that voters believe that the state is bad averaged across media reports. This can be written as:

\footnotetext{
${ }^{27}$ This basic idea, that a lack of media reports might reflect either no information available to the media or government censoring of negative media reports, has played a key role in the theoretical literature on state censorship. Shadmehr and Bernhardt (2015) argue that governments might gain by committing to less censorship since this leads voters to update more favorably towards the government upon receiving no media reports. Guriev and Treisman (2015) develop an informational model in which dictators can survive via manipulation of information, including censorship and propaganda, rather than via more traditional means, such as repression.
} 


$$
\operatorname{Pr}(s=b \mid r)=\operatorname{Pr}(r=b)+\operatorname{Pr}(r=\phi) \operatorname{Pr}(s=b \mid r=\phi)
$$

In the censored environment, we have that $\operatorname{Pr}(r=b)=(1-p) \pi_{b}(1-q)$ and $\operatorname{Pr}(r=\phi)=p+(1-p) \pi_{b} q$. Since the environment is unknown to voters, and using the results from above, this can be written as follows for the censored environment:

$$
\operatorname{Pr}(s=b \mid r)=(1-p) \pi_{b}(1-q)+\left[p+(1-p) \pi_{b} q\right] \frac{\left[p+(1-p) \pi_{c} q\right] \pi_{b}}{\left[p+(1-p) \pi_{c} q\right] \pi_{b}+p\left(1-\pi_{b}\right)}
$$

One can show that this is less than $\pi_{b}$ so long as $\pi_{c}<1.28$ That is, censorship systematically decreases voter perceptions of the bad state. If voters know that the media environment is censored $\left(\pi_{c}=1\right)$, by contrast, then there is no uncertainty over the media environment, and $\operatorname{Pr}(s=b \mid r)=\pi_{b}$. In this case, voters are sufficiently sophisticated to account for censorship when processing content, understanding that censorship implies a loss of access to information that might reflect negatively on the government. This result, that censorship systematically manipulates voter beliefs when $\pi_{c}<1$, highlights the role of voter uncertainty over the censorship environment in manipulating voters. In the extensions below, we further explore how voters might learn about the censorship environment.

\subsection{Extensions}

In this section, we consider five extensions of the model. The first embeds this model of learning into a model of collective action, generating a demand for opposition media. The second and third extensions allow voters to learn about the censorship environment, first from an independent signal about the media environment and then from past media reports. We then consider a model of endogenous censorship in which incumbents, knowing the state, choose the media environment. Finally, we allow for, in addition to state censorship of bad reports, self-censorship of good reports by opposition media. The details of these extensions are provided in the Appendix, and here we just summarize the key results.

In the first extension, we embed our informational model of censorship into a simple model of collective action in which opposition to the government exhibits strategic complementarities. Due to collective action, voters benefit from distinguishing between the media receiving negative information about the government (i.e., bad signals) and the media receiving no information about the government (i.e., no signal).

\footnotetext{
${ }^{28}$ This follows from the fact that the expression equals $\pi_{b}$ when $\pi_{c}=1$ and that the right-hand side is increasing in $\pi_{c}$, meaning that voter perceptions of the bad state decrease as voters uncertainty over the media environment increases (i.e., $\pi_{c}$ falls below 1).
} 
In this sense, voters have a preference for opposition media and censorship reduces voter welfare. In the context of this model, we also show that the government might benefit from increased censorship, via a corresponding reduction in collective action, when censorship levels are low.

In the second extension, we account for the fact that the closing of RCTV was observed by voters 29 In particular, voters now receive an informative signal of the media environment before receiving media reports. This signal could be interpreted as, for example, voters observing that RCTV was replaced by TVES. The key result here is that, unless this signal perfectly reveals the media environment, then voter beliefs are still systematically manipulated by the media environment. That is, censorship systematically decreases voter perceptions of the bad state, when averaged across both states and all possible media reports.

As a third extension, we allow voters to learn about the media environment from both contemporaneous and past media reports. While voters still do not know the media environment, we assume that the environment is stable and voters thus attempt to learn about this over time from media reports. In particular, upon observing no report, voters increase their perceptions that the state is bad, as before, but also now increase their perceptions that the media environment is censored. In the context of a numerical analysis, we show that voters learn the true media environment over time and can account for this when processing media reports. Due to this, and given the results above, voter beliefs over the likelihood of the bad state in the censored environment following media reports converge to the ex-ante probability. That is, $\operatorname{Pr}(s=b \mid r)$ converges to $\pi_{b}$, even in the censored environment. This highlights a crucial difference between the short-run, when voters do not know the censorship environment, and the long-run, when voters learn about this and can use this information when processing media reports.

In a fourth extension, we allow for endogenous state censorship. In particular, the incumbent, knowing whether the state is good or bad, chooses the media environment. We show that, if the costs of censorship are sufficiently low, there is an equilibrium in which censorship is adopted in the bad state but not in the good state. Given this, voters update more negatively upon receiving no report since censorship is now more likely in the bad state. Despite this, incumbent politicians do benefit from censorship in the bad state since it allows them to pool with politicians in the good state.

In the fifth extension, we consider the case in which opposition media might also engage in a form of self censorship. In particular, if opposition media are biased against the government, they might choose to suppress signals revealing that the state is good. Voter updating upon receiving no report is more complicated here as it could reflect one of three situations: the media outlet received no report, state

\footnotetext{
${ }^{29}$ In the Chinese setting, by contrast, citizens are not aware of many forms of censorship. See Roberts (2018).
} 
censorship of bad reports, or self-censorship of good reports by opposition media outlets. Nonetheless, we show that state censorship is still effective in the sense that it lowers, on average, voter perceptions that the state is bad.

\subsection{Summary}

To summarize, the model and the associated extensions can explain our three key empirical findings. First, as developed in the first extension, there is a preference for opposition media, meaning that voters might switch to Globovision, when available, following the closing of RCTV. Second, censorship systematically manipulates voter beliefs in favor of the incumbent, meaning that areas without access to Globovision might experience an increase in support for the government, relative to areas that retained access to opposition television, following the closing of RCTV. Third, as developed in the third extension, voters rationally adjust to the media environment in the long run, and beliefs are not systematically manipulated by censorship. This explains the fading of the gap in support for Chavez between areas with and without access to Globovision following the closing of RCTV.

\section{Conclusion}

This paper investigates the role of government censorship of opposition television in the accountability of governments and incumbent politicians. We focus on the expiration of the television license of RCTV, a key opposition channel in Venezuela, and the subsequent opening of TVES, a public channel. The closure of RCTV, along with the limited signal availability of Globovision, provide a natural experiment in which some areas lose access to opposition television overnight, while other areas retain access to opposition news. Using ratings data, we first find that viewers switched from TVES, the public pro-government channel, to Globovision, the only other opposition channel, in areas with access to the broadcast signal

following the closing of RCTV. Building upon this result, we find that Chavez approval ratings fell in these areas that retained access to opposition television via the Globovision broadcast signal, relative to areas without access to the signal, following the closing of RCTV. We also find evidence that access to the Globovision signal is associated with a reduction in support for foreign allies and an increase in support for foreign enemies. We find similar patterns in electoral data, with support for Chavez falling in these areas that retained access to opposition television via the Globovision broadcast signal, relative to areas without access to the signal, following the closing of RCTV. In both analyses, differences between 
areas with and without Globovision fade over time. Taken together, these results suggest that viewers are sufficiently sophisticated to adjust their viewing patterns in response to government censorship, and counterfactuals document that these behavioral responses contribute towards an economically significant reduction in support for government. In addition, voters are sufficiently sophisticated to adjust to the censored environment in the long run, understanding that a lack of information might reflect negatively upon the government. By both adjusting their media consumption patterns and rationally filtering information in a censored environment, voters can limit the effects of censorship and better hold governments and incumbent politicians accountable. 


\section{References}

Adena, Maja, Ruben Enikolopov, Maria Petrova, Veronica Santarosa and Ekaterina Zhuravskaya. 2015. "Radio and the rise of the Nazis in pre-war Germany." Quarterly Journal of Economics 130(4):1885-1939.

Besley, Timothy and Andrea Prat. 2006. "Handcuffs for the Grabbing Hand? Media Capture and Government Accountability." The American Economic Review pp. 720-736.

Besley, Timothy and Robin Burgess. 2002. "The political economy of government responsiveness: Theory and evidence from India." The Quarterly Journal of Economics 117(4):1415-1451.

Chang-Tai, Hsieh, Edward Miguel, Daniel Ortega and Francisco Rodriguez. 2011. "The Price of Political Opposition: Evidence from Venezuela's Maisanta." American Economic Journal: Applied Economics 3(2):196-214.

Chen, Yuyu and David Yang. 2019. “The Impact of Media Censorship: 1984 or Brave New World." Working Paper.

Chiang, Chun-Fang and Brian Knight. 2011. "Media bias and influence: Evidence from newspaper endorsements." The Review of Economic Studies 78(3):795-820.

Corrales, Javier and Michael Penfold. 2011. Dragon in the Tropics: Hugo Chavez and the Political Economy of Revolution in Venezuela. Washington D.C.,U.S: Brookings Latin America Initiative Books.

DellaVigna, Stefano and Ethan Kaplan. 2007. "The Fox News effect: Media bias and voting." The Quarterly Journal of Economics 122(3):1187-1234.

Dinneen, Mark. 2012. "The Chavez government and the battle over the media in Venezuela." Asian Journal of Latin American Studies 25(2):27-53. 
Durante, Ruben and Brian Knight. 2012. "Partisan Control, Media Bias, And Viewer Responses: Evidence From Berlusconi'S Italy.” Journal of the European Economic Association 10(3):451-481.

Durante, Ruben, Paolo Pinotti and Andrea Tesei. 2017. The Political Legacy of Entertainment TV. Technical report Centre for Economic Performance, LSE.

Edmond, Chris. 2013. "Information manipulation, coordination, and regime change." Review of Economic Studies 80(4):1422-1458.

Enikolopov, Ruben, Alexey Makarin, Maria Petrova and Leonid Polishchuk. 2019. "Social image, networks, and protest participation.”.

Enikolopov, Ruben, Maria Petrova and Ekaterina Zhuravskaya. 2011. "Media and political persuasion: Evidence from Russia.” The American Economic Review 101(7):3253-3285.

EU-EOM. 2006. Final Report: Presidential Elections Venezuela 2006. Technical report European Union Election Observation Mission.

Ferraz, Claudio and Frederico Finan. 2008. "Exposing corrupt politicians: the effects of Brazil's publicly released audits on electoral outcomes." The Quarterly journal of economics 123(2):703-745.

Ferraz, Claudio and Frederico Finan. 2011. "Electoral accountability and corruption: Evidence from the audits of local governments." American Economic Review 101(4):1274-1311.

Gentzkow, Matthew and Jesse M Shapiro. 2010. "What drives media slant? Evidence from US daily newspapers." Econometrica 78(1):35-71.

Gentzkow, Matthew, Jesse M Shapiro and Michael Sinkinson. 2011. "The Effect of Newspaper Entry and Exit on Electoral Politics.” American Economic Review 101(7):2980-3018. 
George, Lisa and Joel Waldfogel. 2003. "Who affects whom in daily newspaper markets?" Journal of Political Economy 111(4):765-784.

Gerber, Alan S., Dean Karlan and Daniel Bergan. 2009. "Does the Media Matter? A Field Experiment Measuring the Effect of Newspapers on Voting Behavior and Political Opinions." American Economic Journal: Applied Economics 1(2):35-52.

Guriev, Sergei and Daniel Treisman. 2015. How modern dictators survive: An informational theory of the new authoritarianism. Technical report National Bureau of Economic Research.

King, Gary, Jennifer Pan and Margaret E Roberts. 2013. "How censorship in China allows government criticism but silences collective expression.” American Political Science Review 107(2):326-343.

Knight, Brian and Ana Tribin. 2019. “The Limits of Propaganda: Evidence from Chavez's Venezuela." Journal of the European Economic Association .

Kronick, Dorothy and John Marshall. 2018. “Opposition Media and Political Accountability: Evidence from Venezuela.”.

Martin, Gregory and Ali Yurukoglu. 2017. "Bias in Cable News: Persuasion and Polarization.”. American Economic Review.

Martin, Gregory J and Joshua McCrain. 2019. "Local news and national politics.” American Political Science Review 113(2):372-384.

Mullainathan, Sendhil and Andrei Shleifer. 2005. "The market for news.” American Economic Review pp. 1031-1053.

Nelson, Brian A. 2009. The Silence and the Scorpion: The Coup Against Chavez and the Making of Modern Venezuela. New York, U.S: Nation Books.

Prat, Andrea. 2018. "Media Power.”. Journal of Political Economy. 
Reporters Without Borders. 2003. Venezuela: Caught Between an Authoritarian President and an Intolerance Media. Technical report Reporters Without Borders.

Roberts, Margaret E. 2018. Censored: Distraction and Diversion Inside China's Great Firewall. Princeton, NJ: Princeton University Press.

Shadmehr, Mehdi and Dan Bernhardt. 2015. "State censorship." American Economic Journal: Microeconomics 7(2):280-307.

Snyder, James M and David Stromberg. 2010. "Press Coverage and Political Accountability." Journal of Political Economy 118(2):355-408.

Szeidl, Adam and Ferenc Szucs. 2017. "Media Capture Through Favor Exchange.”.

Weisbrot, Mark and Tara Ruttenberg. 2010. Television in Venezuela: Who Dominates the Media? Technical report Center For Economic and Policy Research.

Wilpert, Gregory. 2007. Changing Venezuela by Taking Power: The History and Policies of the Chavez Government. London, England: Verso Books. 


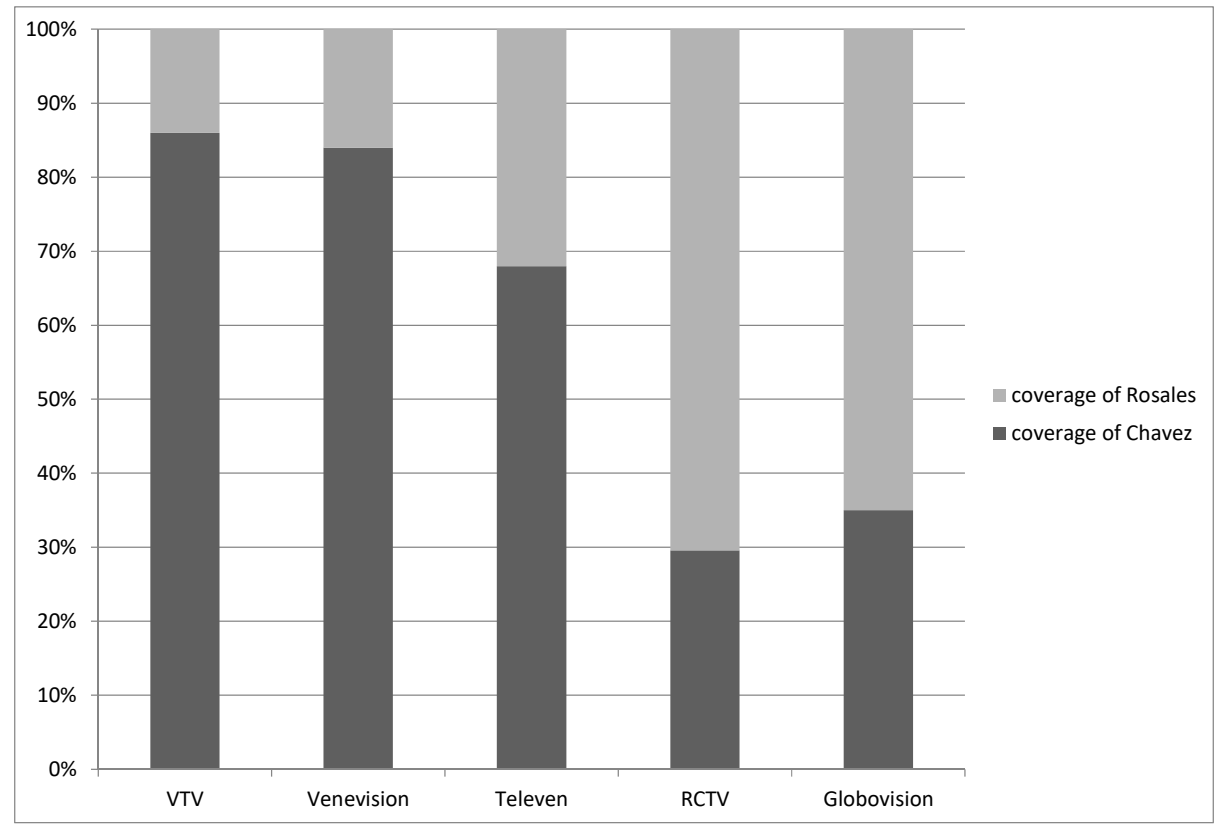

Figure 1: EU Media Monitoring of 2006 Presidential Election

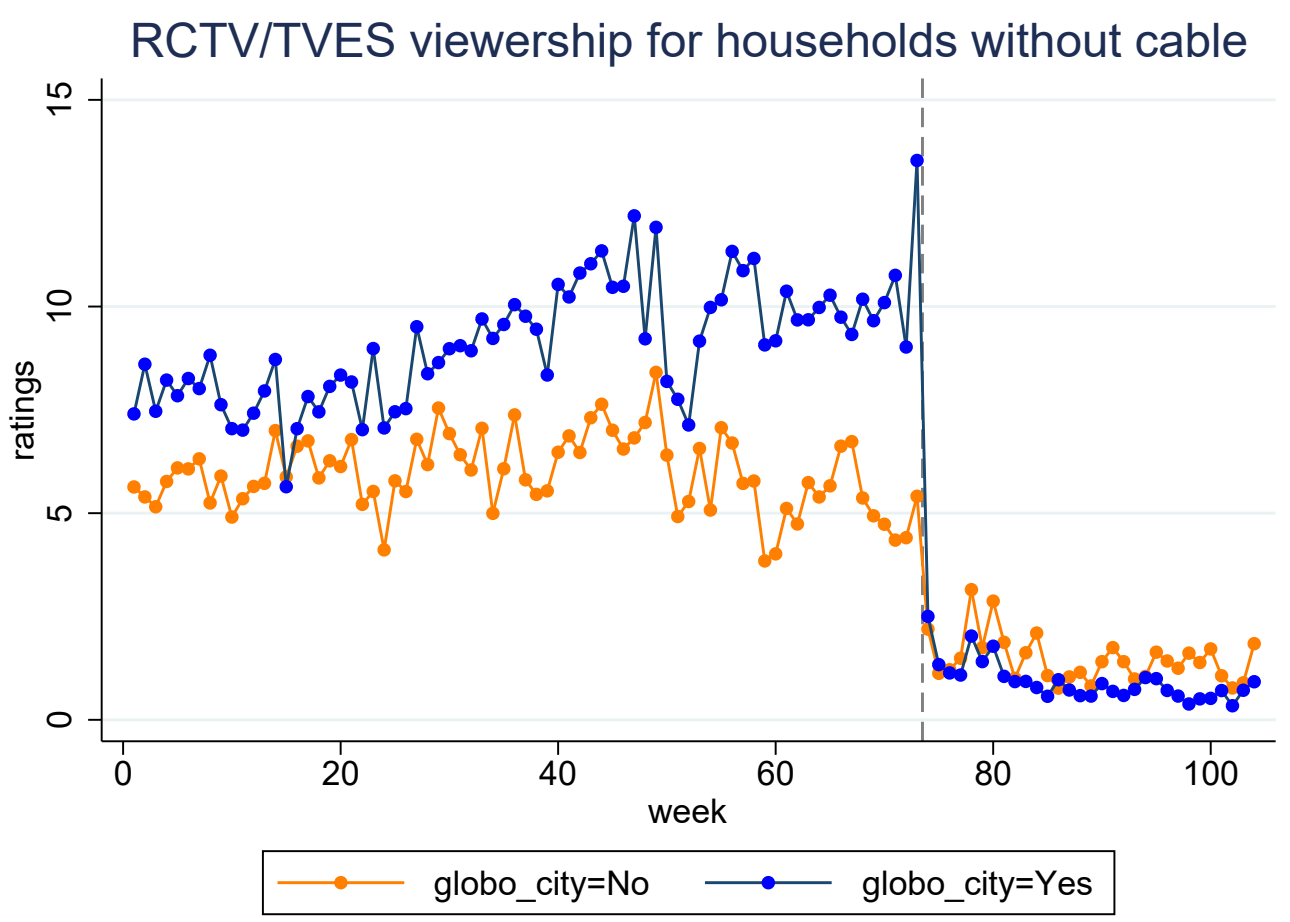

Figure 2 


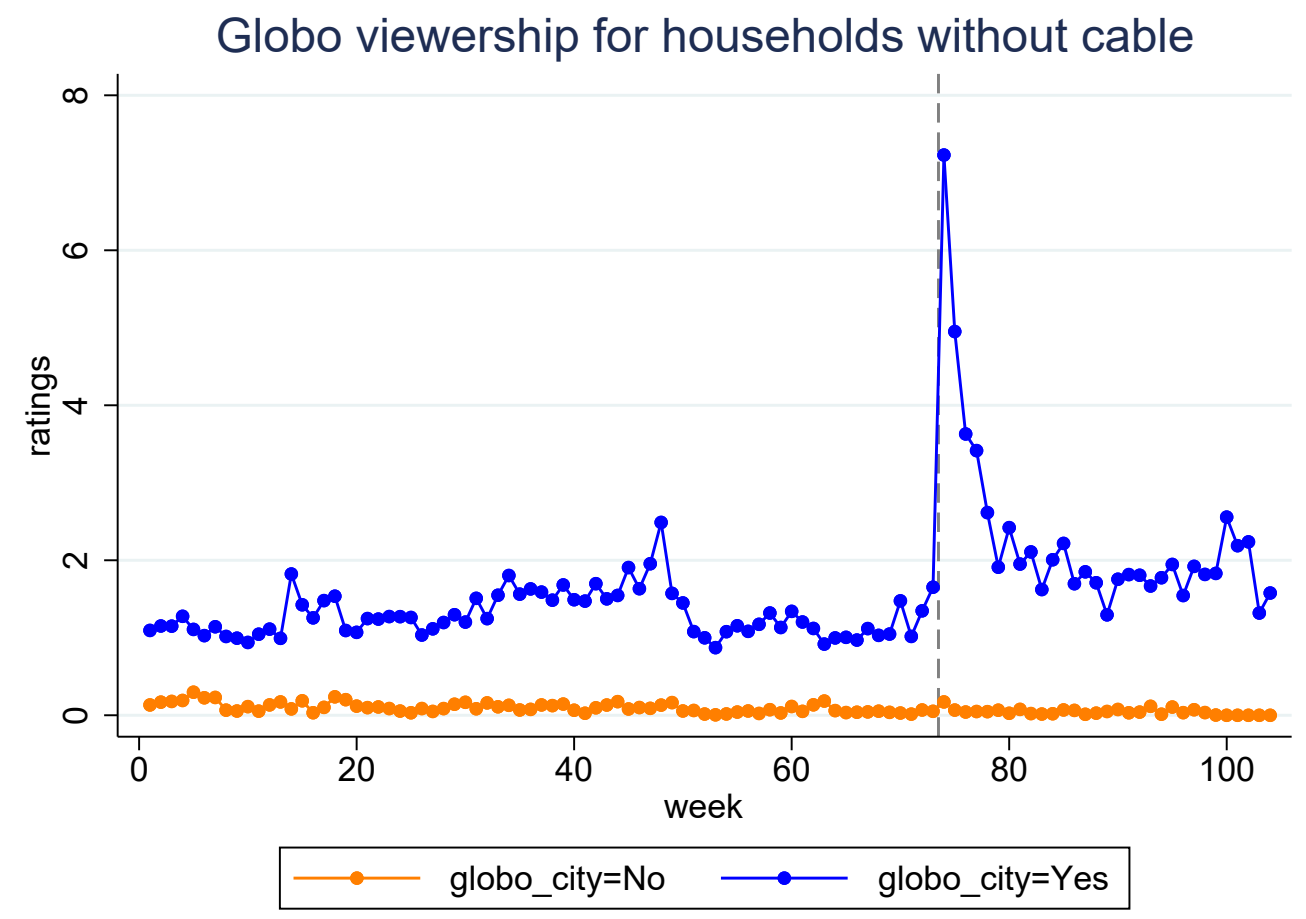

Figure 3

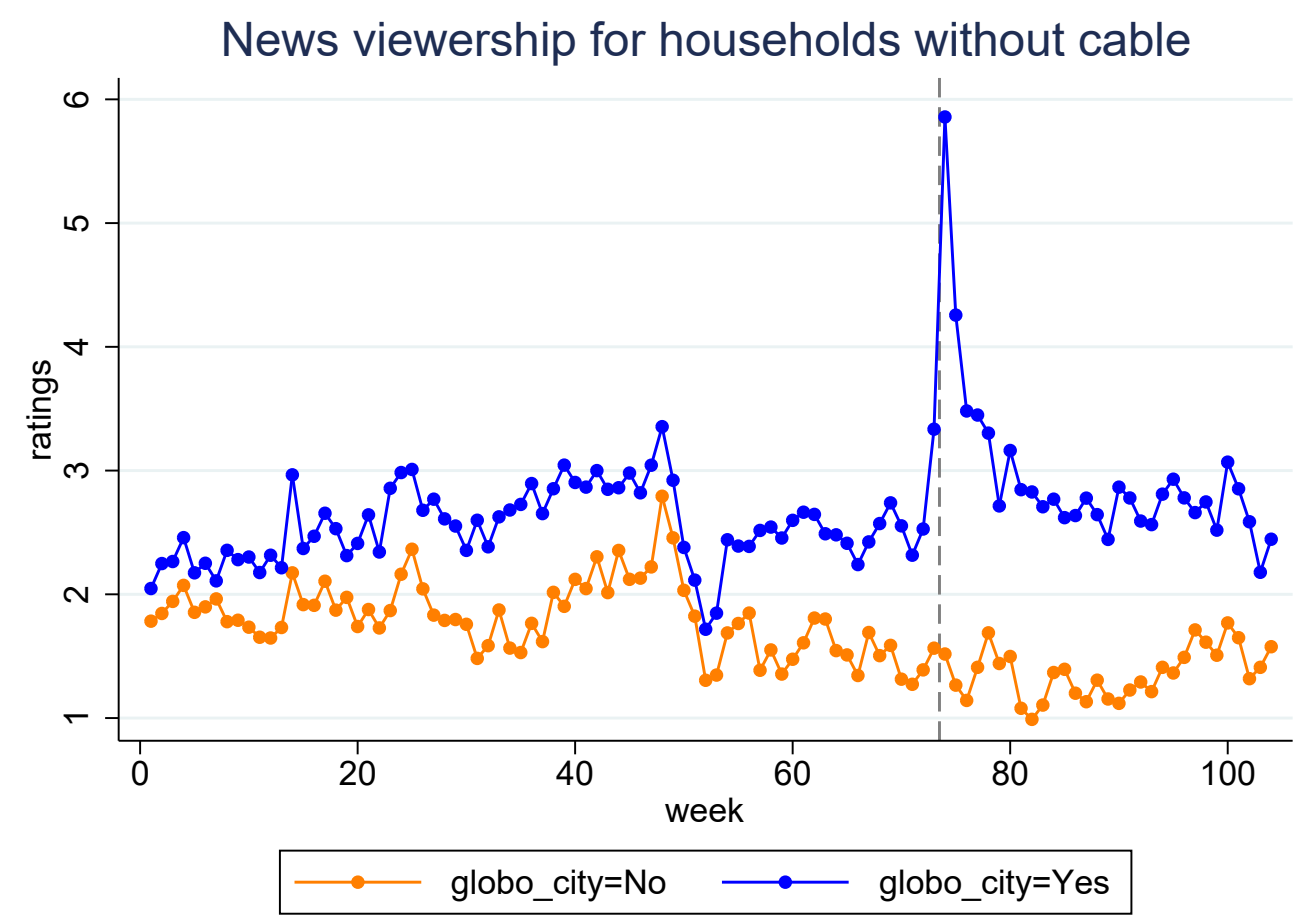

Figure 4 


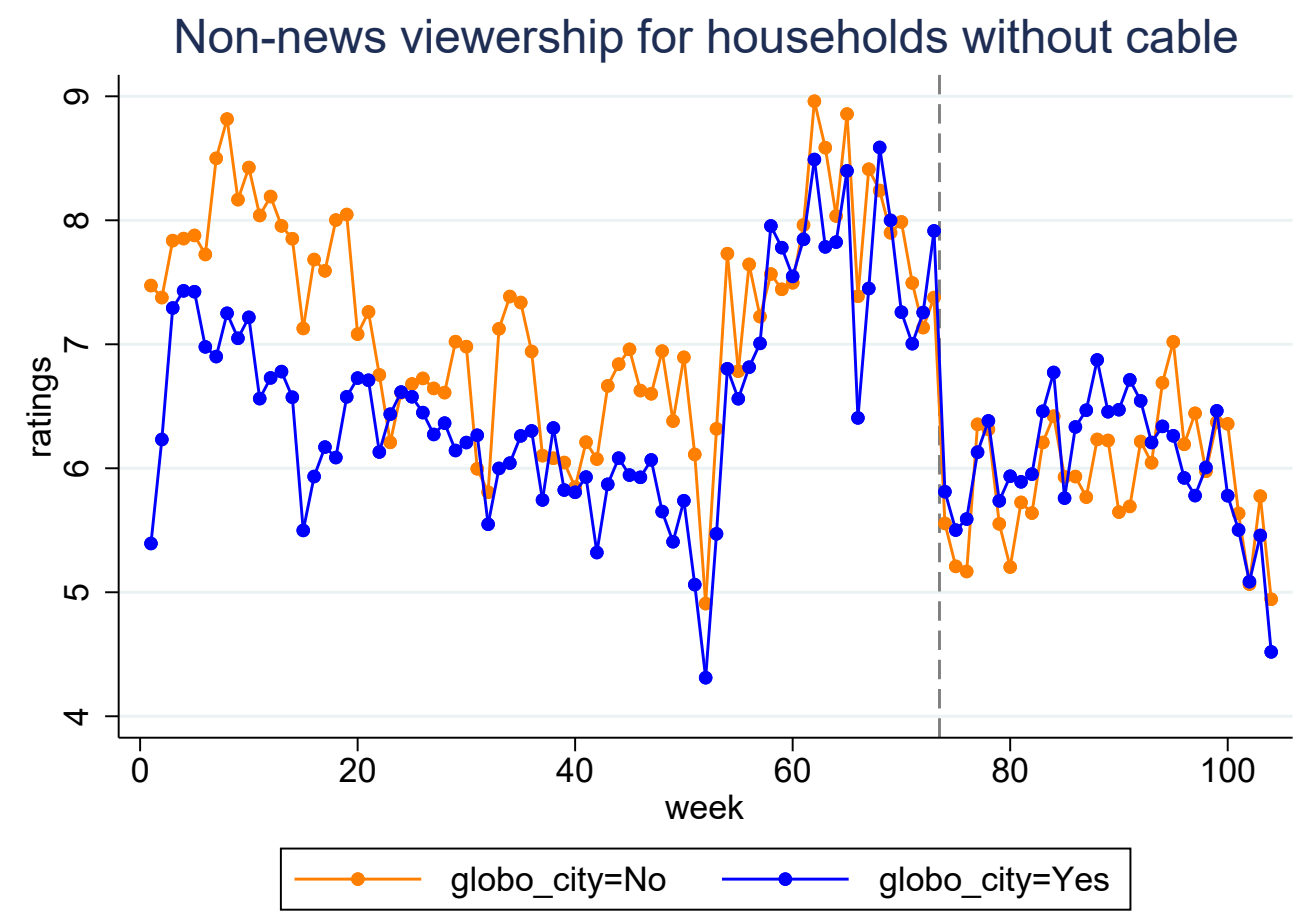

Figure 5

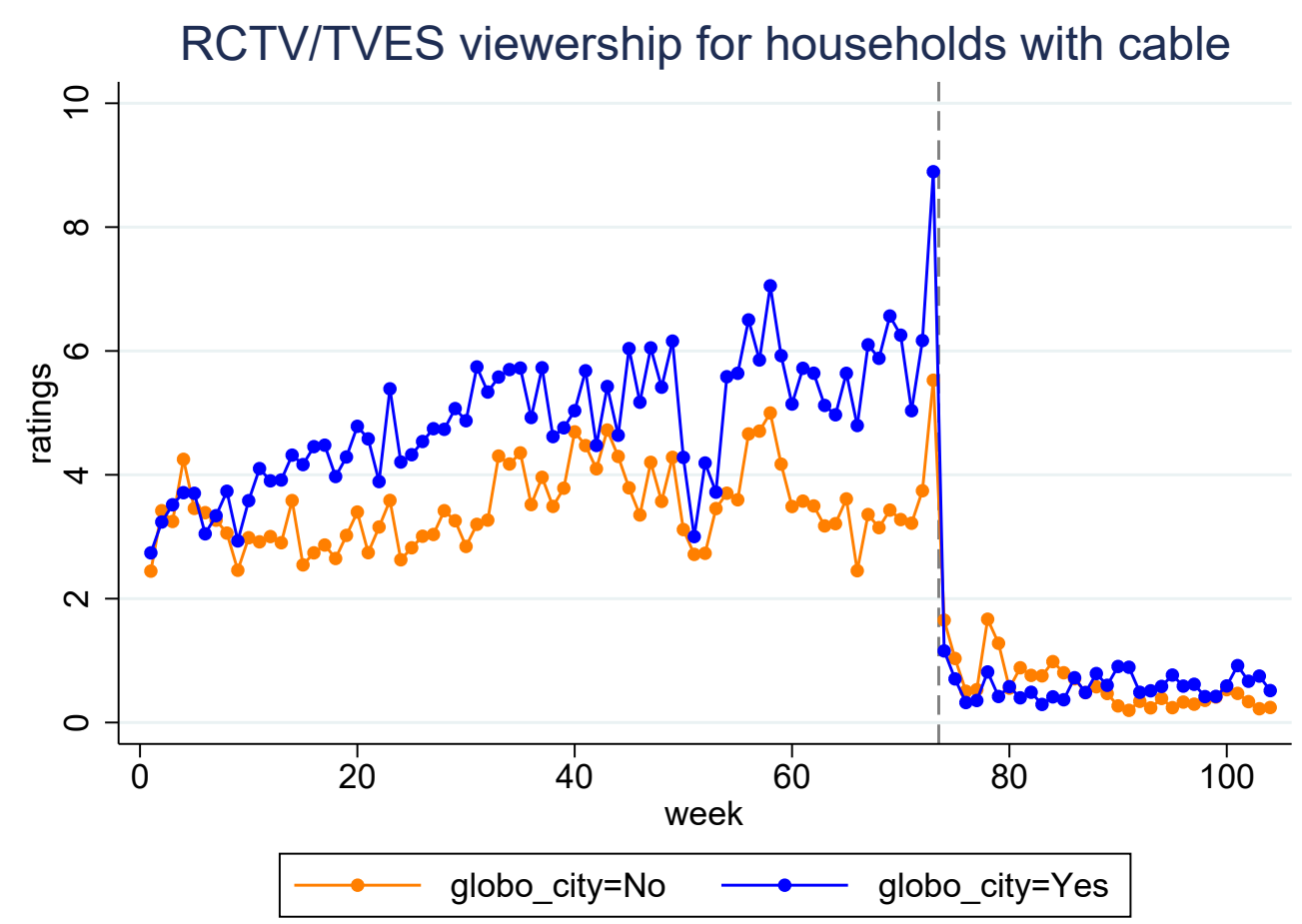

Figure 6 


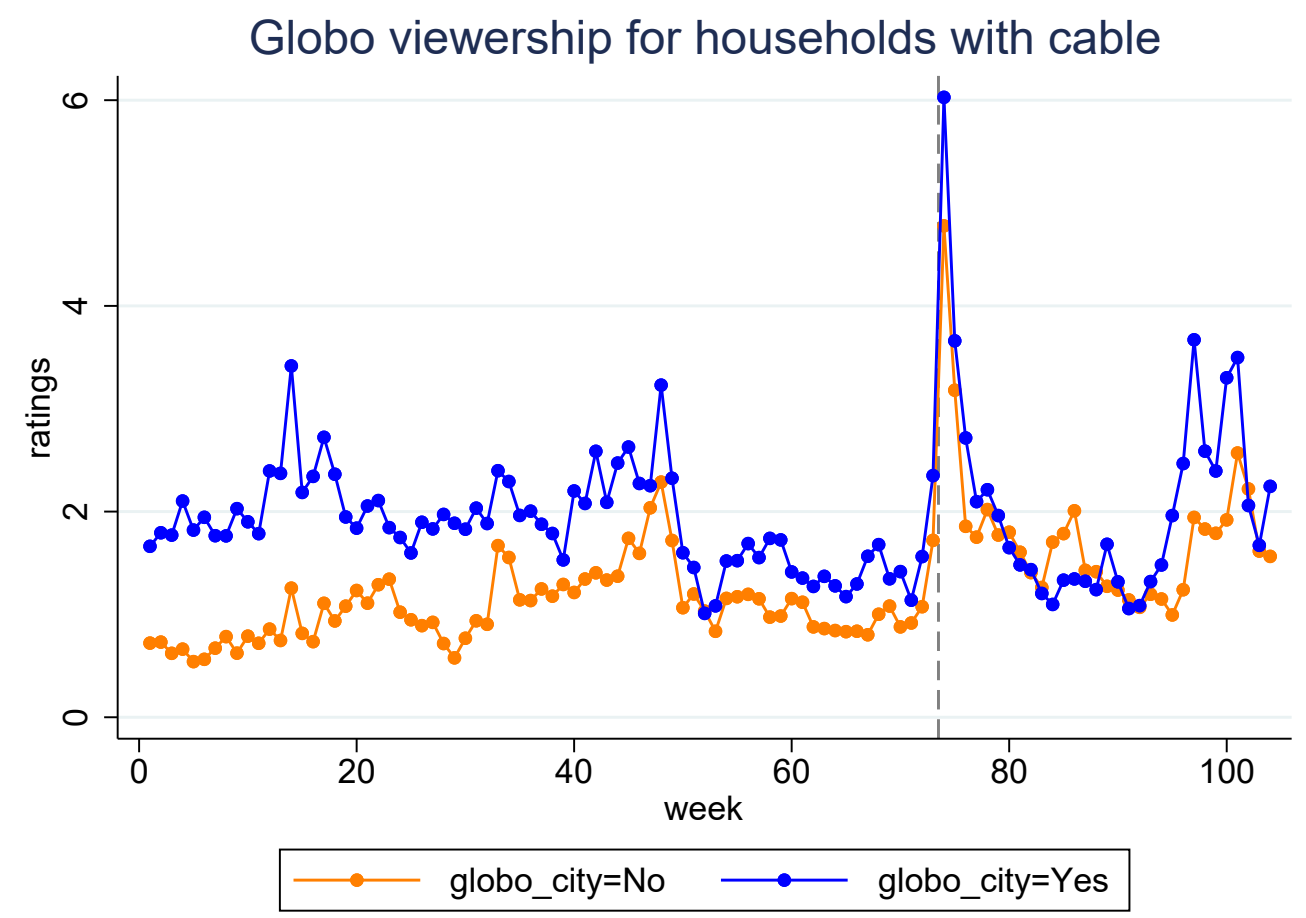

Figure 7

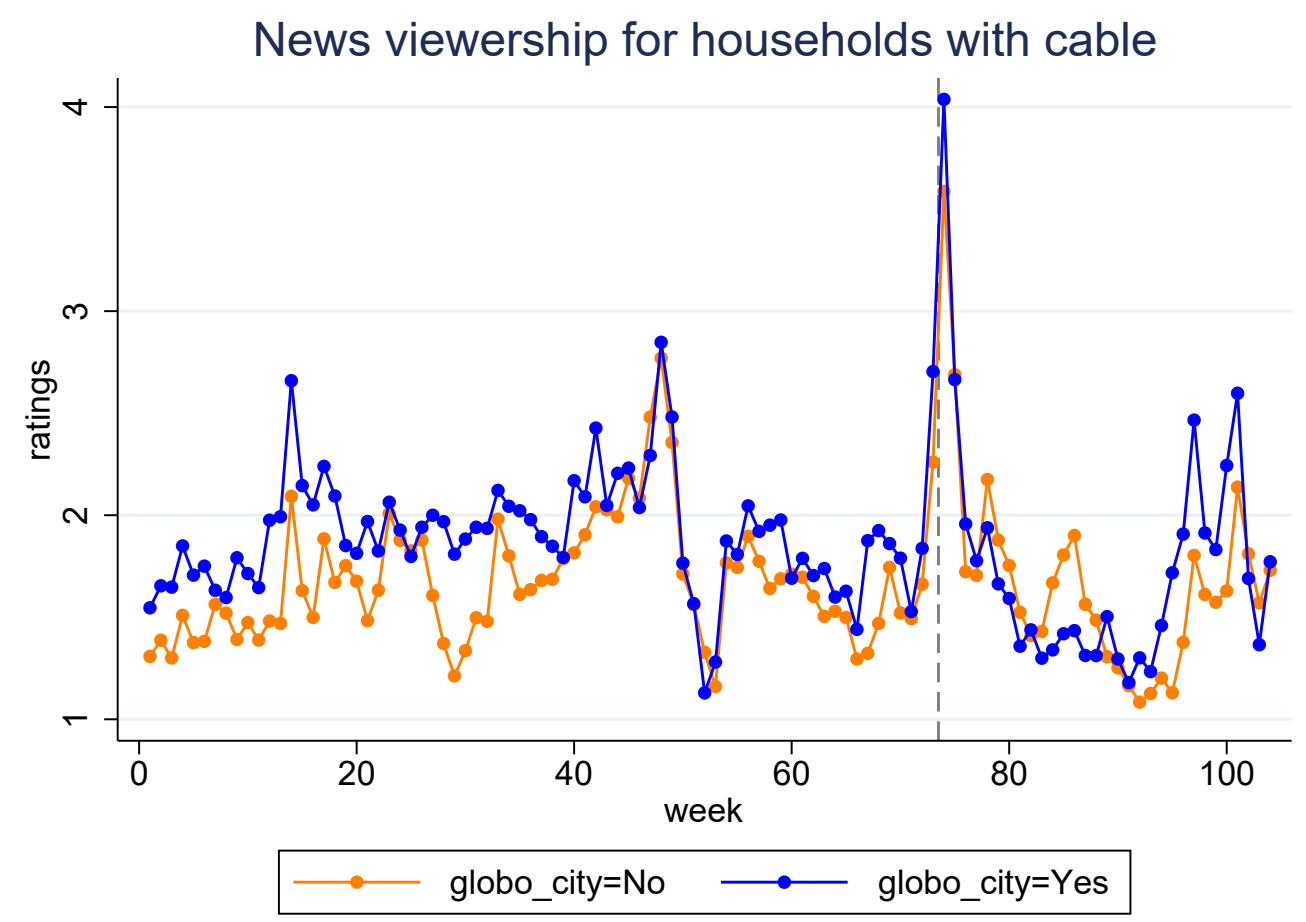

Figure 8 


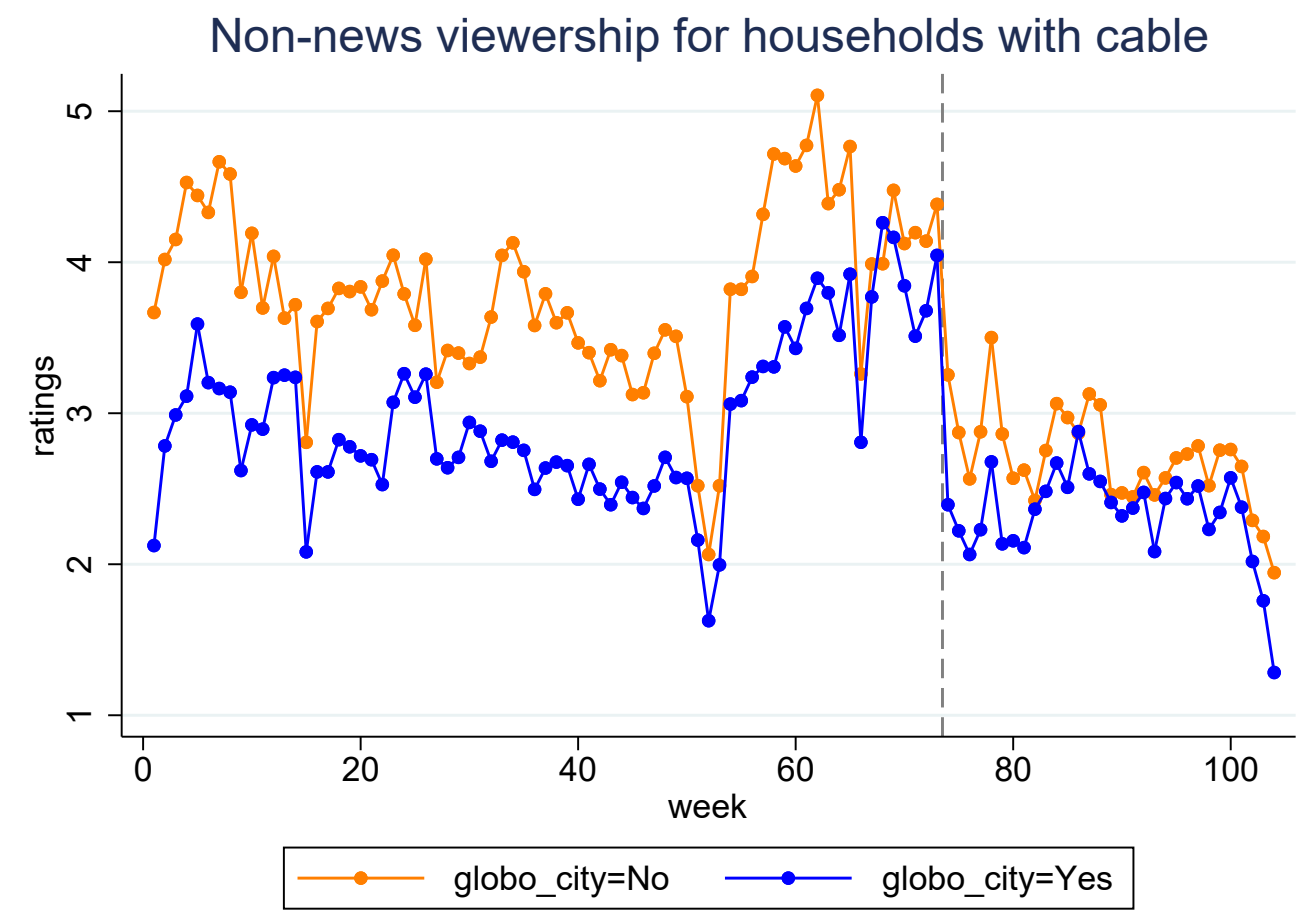

Figure 9

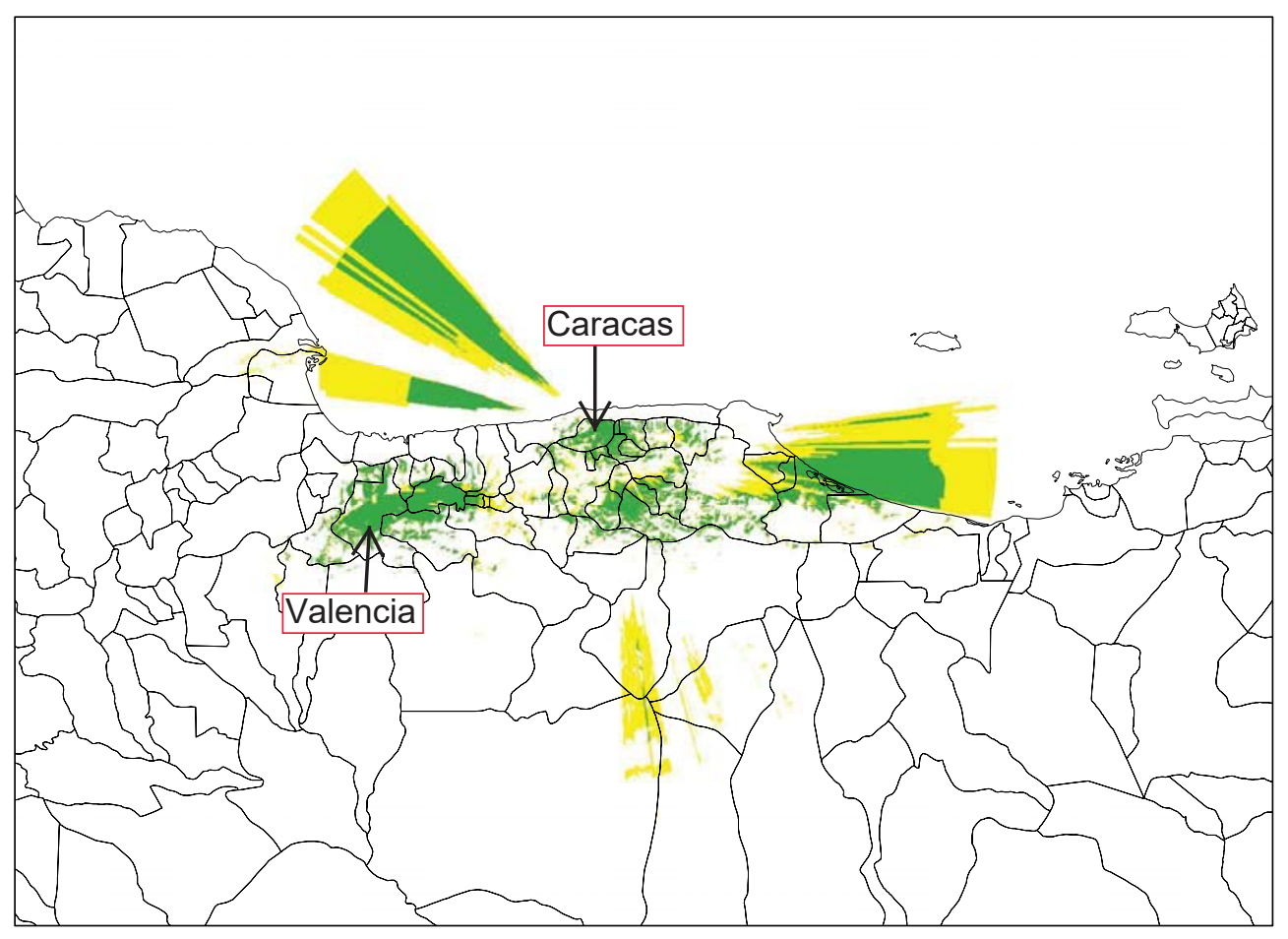

Figure 10: Globovision coverage map 


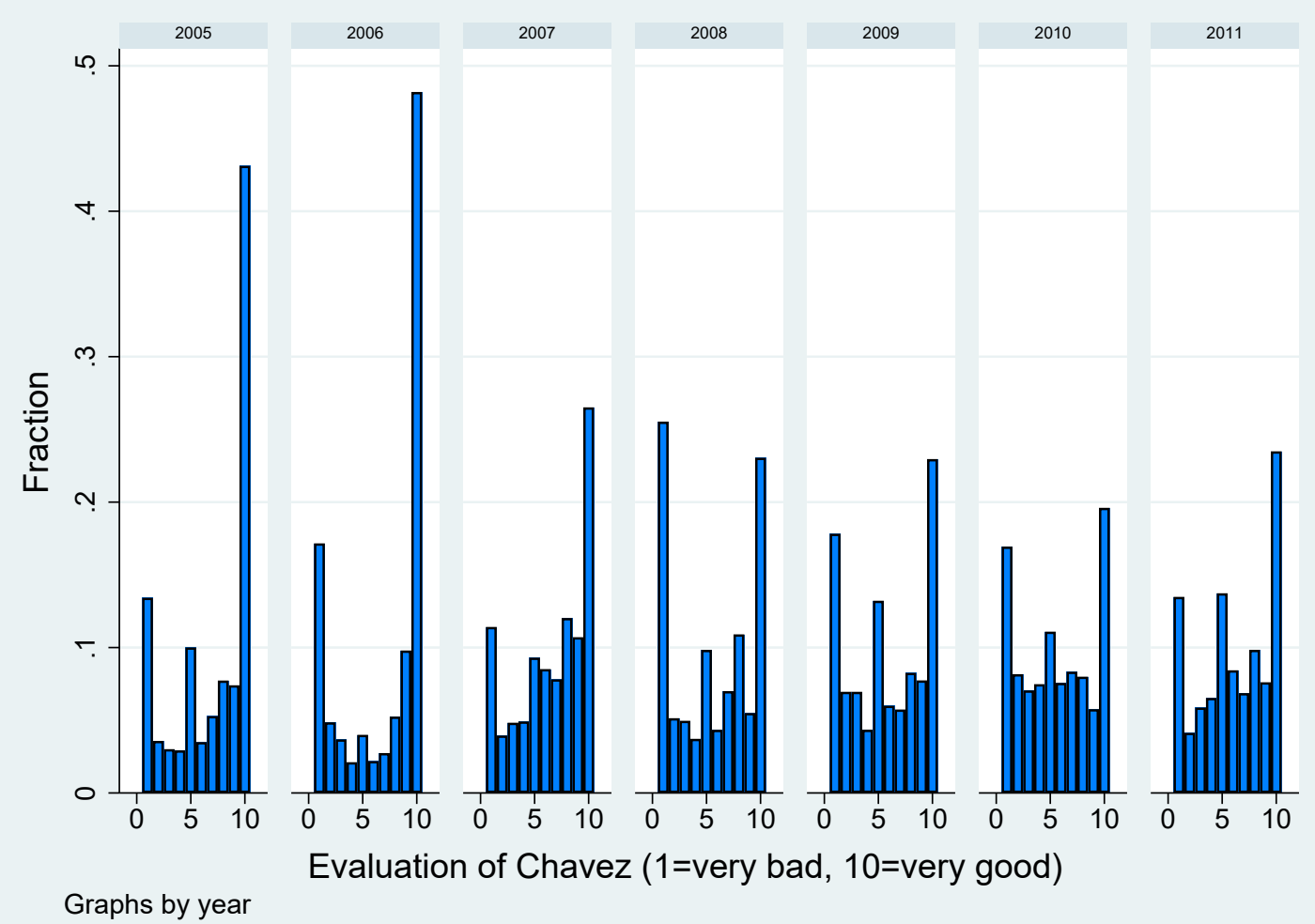

Figure 11

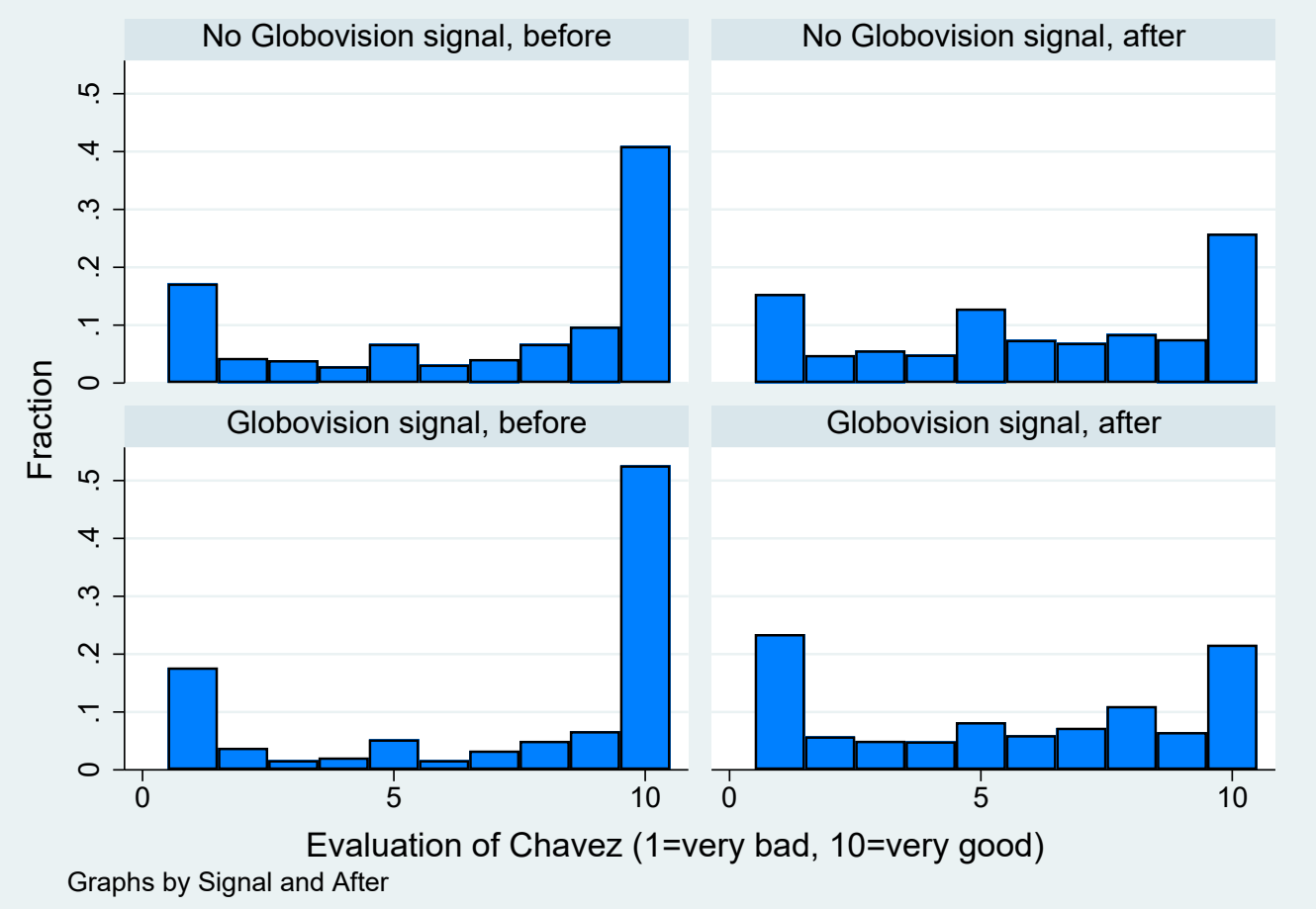

Figure 12 


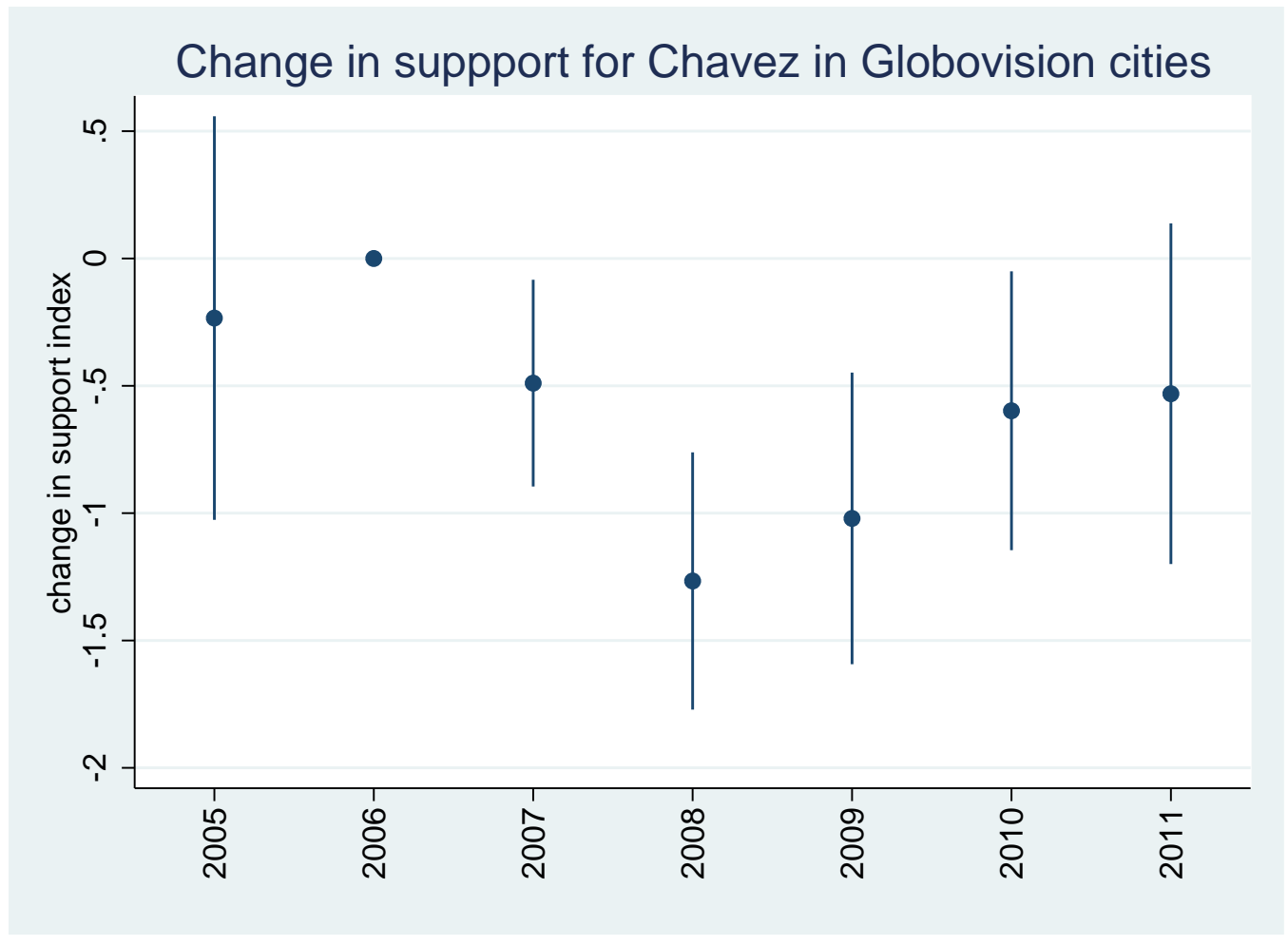

Figure 13

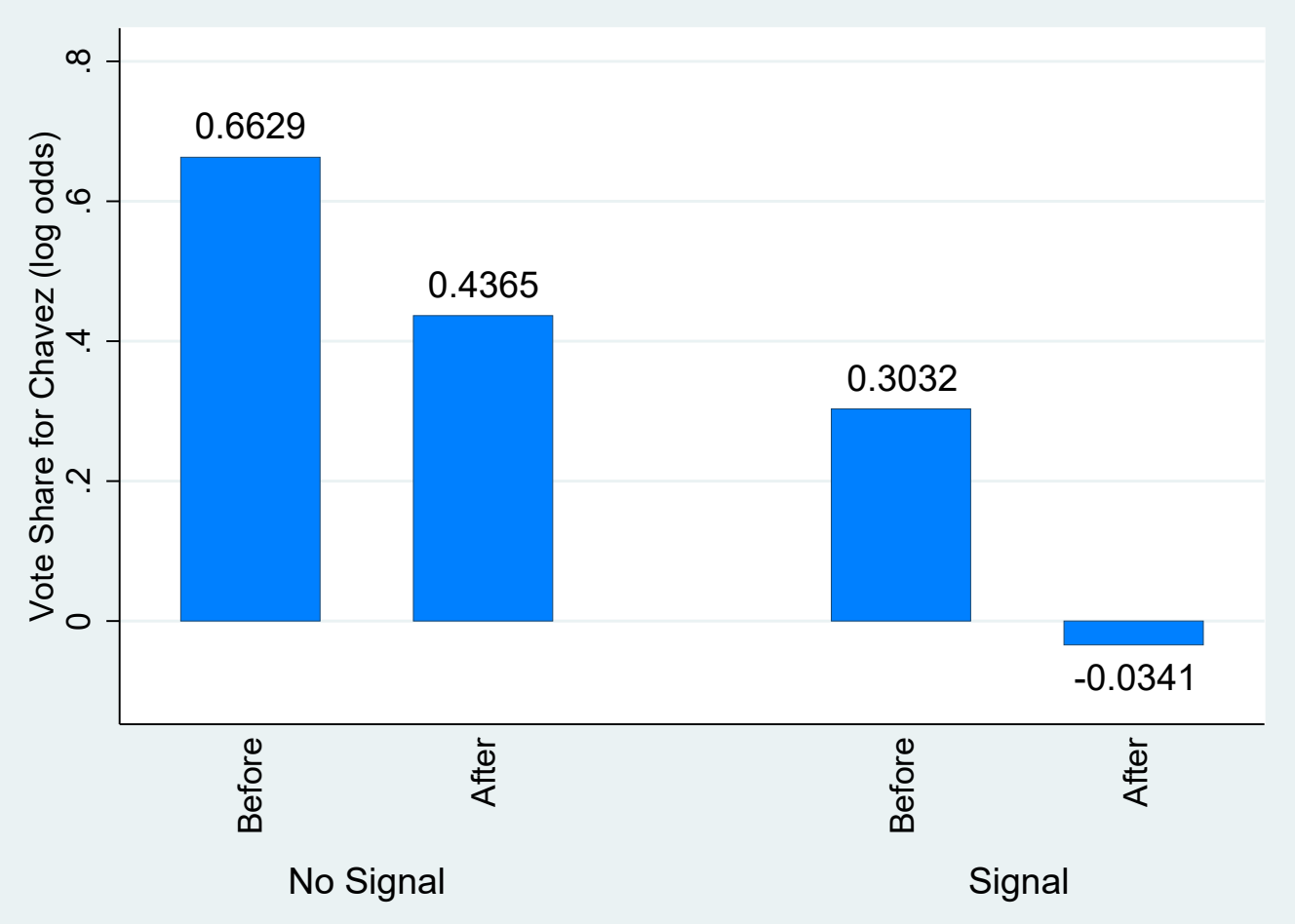

Figure 14 


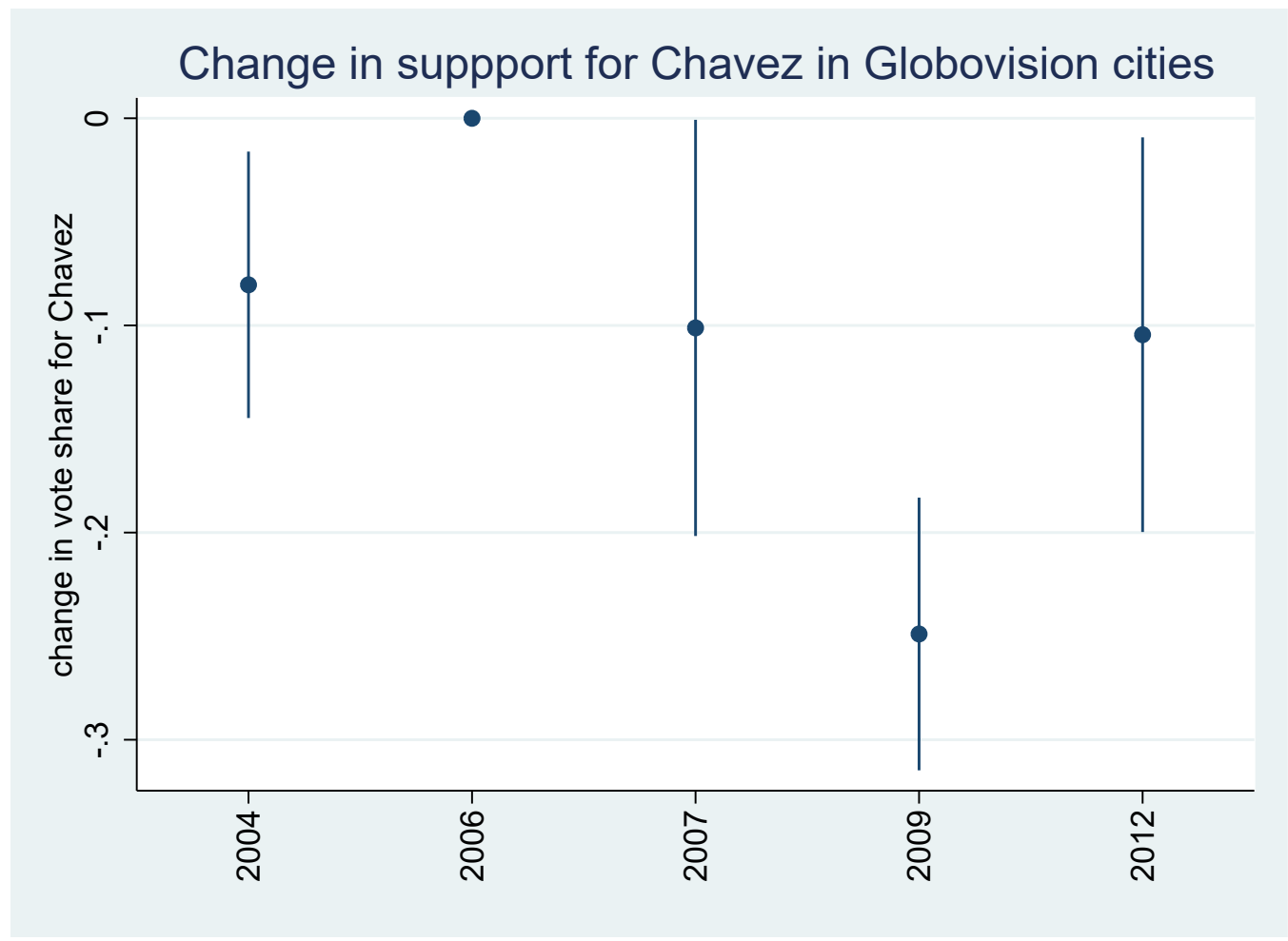

Figure 15

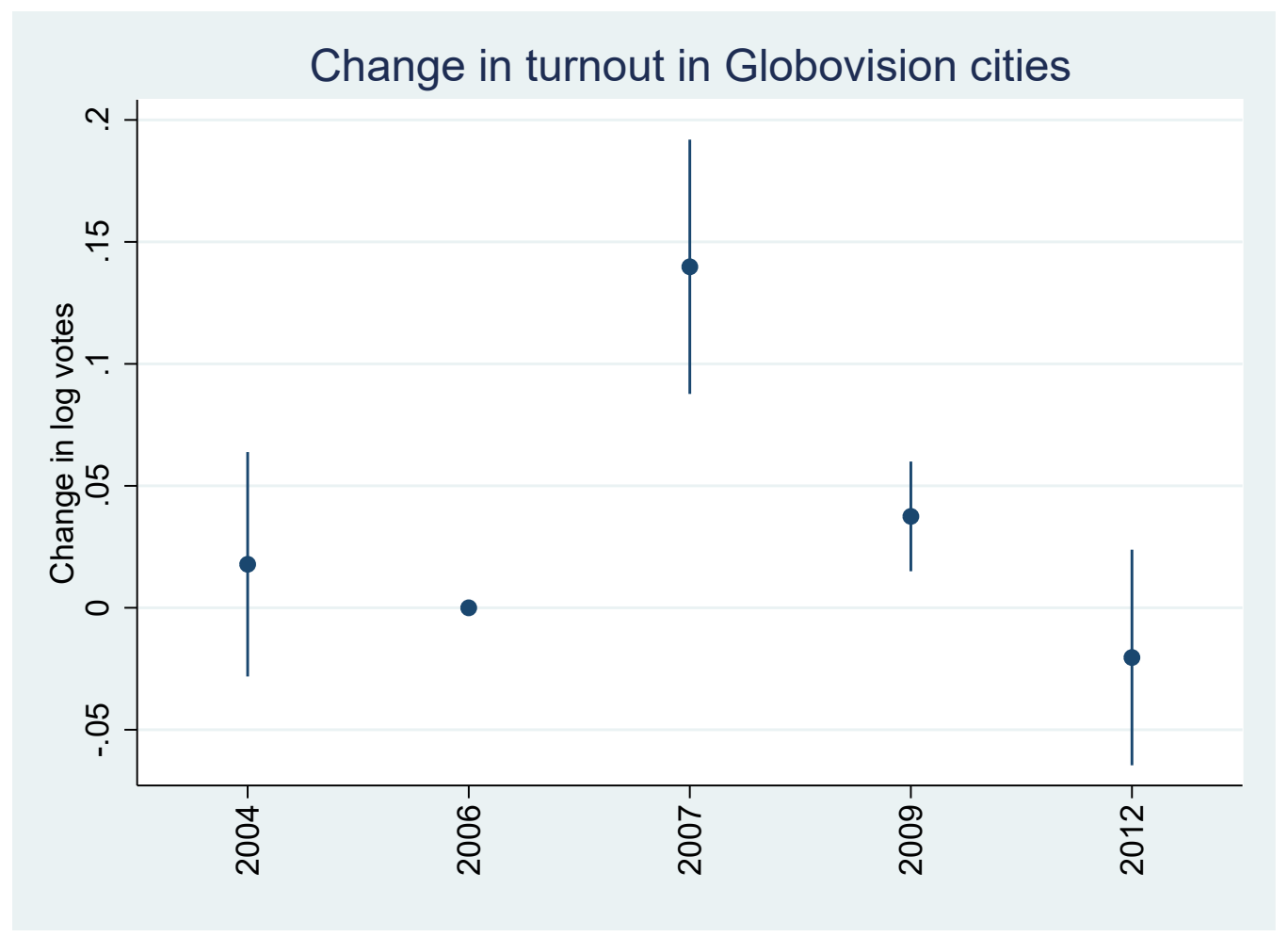

Figure 16 


\section{Vote Change in Globo Cites: Counterfactual Scenarios}

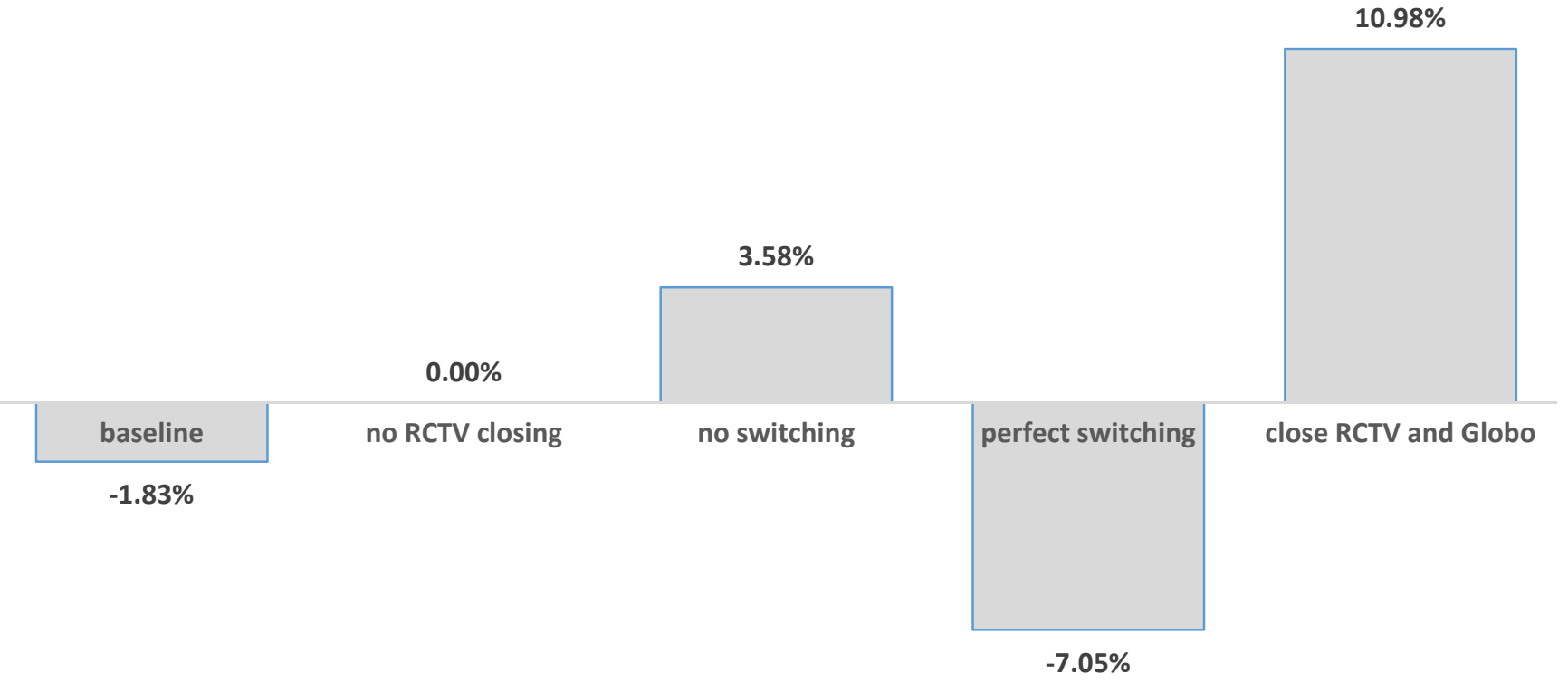

Figure 17

Table 1: Key Television Channels

\begin{tabular}{|c|c|c|c|c|}
\hline Channels & Ownership/Ideology & Metro Areas & Dates & Daily News Hours \\
\hline \hline Globovision & Private/Opposition & Caracas and Valencia & all & 19.57 \\
\hline RCTV & Private/Opposition & National & Until May 27, 2007 & 4.10 \\
\hline TVES & Public & National & Starting May 28, 2007 & 3.01 \\
\hline Televen & Private/Moderate & National & all & 3.83 \\
\hline Venevision & Private/Moderate & National & all & 3.65 \\
\hline VTV & Public & National & all & 14.62 \\
\hline
\end{tabular}


Table 2: Cable Subscription Rates by Year for Venezuela

\begin{tabular}{|c|c|c|c|}
\hline Year & Subscribers & Households & $\begin{array}{c}\text { Penetration } \\
\text { rate }\end{array}$ \\
\hline \hline 2000 & 778,904 & $4,685,917$ & $16.62 \%$ \\
\hline 2001 & 977,375 & $4,998,022$ & $19.56 \%$ \\
\hline 2002 & 943,327 & $5,185,460$ & $18.19 \%$ \\
\hline 2003 & 882,322 & $5,533,395$ & $15.95 \%$ \\
\hline 2004 & 981,368 & $5,754,516$ & $17.05 \%$ \\
\hline 2005 & $1,117,553$ & $6,215,837$ & $17.98 \%$ \\
\hline 2006 & $1,336,309$ & $6,364,119$ & $21.00 \%$ \\
\hline 2007 & $1,608,279$ & $6,476,233$ & $24.83 \%$ \\
\hline 2008 & $1,929,262$ & $6,658,321$ & $28.98 \%$ \\
\hline 2009 & $2,192,519$ & $6,803,942$ & $32.22 \%$ \\
\hline 2010 & $2,550,830$ & $6,969,151$ & $36.60 \%$ \\
\hline 2011 & $2,798,577$ & $7,079,559$ & $39.53 \%$ \\
\hline 2012 & $3,404,298$ & $7,185,754$ & $47.38 \%$ \\
\hline
\end{tabular}

\section{Summary: Consumption of Opposition Television}

\begin{tabular}{|c|c|c|c|}
\hline Panel A: Globo cities ratings (AMR) & before & after & change \\
\hline RCTV & $8.91 \%$ & $0.00 \%$ & $-8.91 \%$ \\
\hline Globovision & $1.30 \%$ & $2.25 \%$ & $0.95 \%$ \\
\hline Panel B: Globo cities average weekly minutes & before & after & change \\
\hline RCTV & 153.43 & 0.00 & -153.43 \\
\hline Globovision & 106.85 & 184.94 & 78.08 \\
\hline total & 260.28 & 184.94 & -75.35 \\
\hline implied switching rate & & & $50.89 \%$ \\
\hline Panel C: non-Globo cities ratings (AMR) & before & after & change \\
\hline RCTV & $5.91 \%$ & $0.00 \%$ & $-5.91 \%$ \\
\hline Globovision & $0.00 \%$ & $0.00 \%$ & $0.00 \%$ \\
\hline Panel D: non-Globo cities average weekly minutes & before & after & change \\
\hline RCTV & 101.77 & 0.00 & -101.77 \\
\hline Globovision & 0.00 & 0.00 & 0.00 \\
\hline total & 101.77 & 0.00 & -101.77 \\
\hline implied switching rate & & & $0.00 \%$ \\
\hline
\end{tabular}

Table 3 


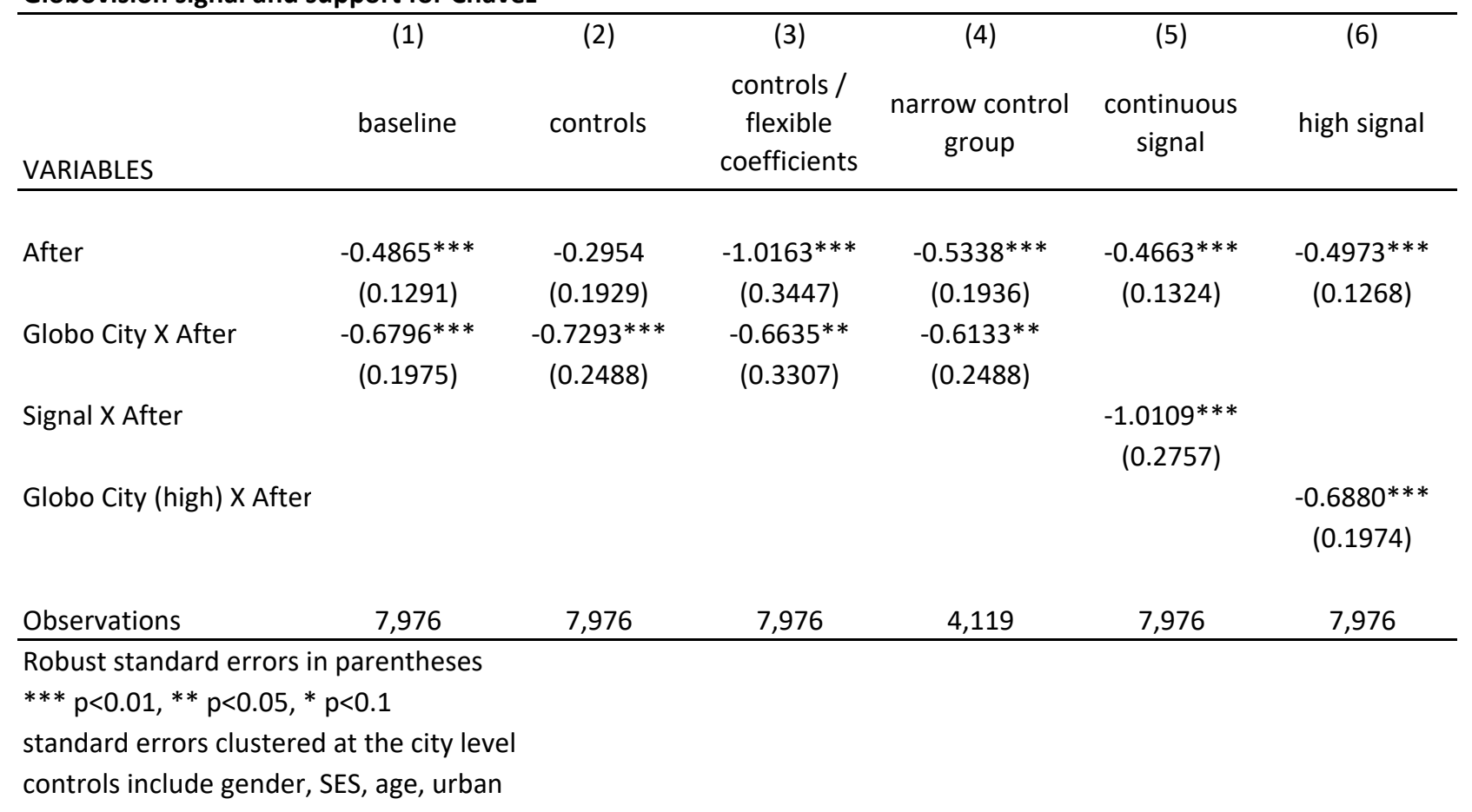

Table 4

Placebo Timing

(1)

1 year before
(2)

VARIABLES baseline
(3)
(4)
(5)

(6)

\begin{tabular}{|c|c|c|c|c|c|c|}
\hline \multirow[t]{2}{*}{ After } & $-0.3732 * *$ & $-0.4865 * * *$ & $-0.3137 * *$ & -0.1283 & -0.0926 & 0.1185 \\
\hline & (0.1791) & (0.1291) & $(0.1548)$ & $(0.0985)$ & (0.0989) & (0.1101) \\
\hline \multirow[t]{2}{*}{ Globo City X After } & -0.4591 & $-0.6796 * * *$ & $-0.5838 * * *$ & -0.0644 & 0.1945 & 0.3095 \\
\hline & $(0.3887)$ & $(0.1975)$ & $(0.1795)$ & $(0.1877)$ & $(0.2335)$ & $(0.2366)$ \\
\hline Observations & 7,976 & 7,976 & 7,976 & 7,976 & 7,976 & 7,976 \\
\hline Log-Likelihood & -16259 & -16221 & -16244 & -16277 & -16279 & -16275 \\
\hline
\end{tabular}

Table 5 
Globovision signal and other outcomes

\begin{tabular}{lccccc}
\hline VARIABLES & $(1)$ & $\begin{array}{c}(2) \\
\text { approve } \\
\text { government }\end{array}$ & approve castro & $\begin{array}{c}(4) \\
\text { approve } \\
\text { uribe/santos }\end{array}$ & $\begin{array}{c}(5) \\
\text { approve us } \\
\text { president }\end{array}$ \\
\hline After & -0.2209 & $-0.4860^{* * *}$ & $-0.6042^{* * *}$ & $-0.6661^{* * *}$ & $0.9184^{* * *}$ \\
& $(0.2909)$ & $(0.1522)$ & $(0.1735)$ & $(0.2231)$ & $(0.2063)$ \\
Globo City X After & 0.1754 & -0.2247 & $-0.6057^{*}$ & $0.4528^{*}$ & 0.2681 \\
& $(0.3014)$ & $(0.1691)$ & $(0.3661)$ & $(0.2431)$ & $(0.2368)$ \\
Observations & 6,890 & 7,666 & 7,727 & 4,582 & 6,934 \\
\hline
\end{tabular}

Robust standard errors in parentheses

*** $p<0.01,{ }^{* *} p<0.05,{ }^{*} p<0.1$

standard errors clustered at the city level

Table 6

Globovision signal and electoral support for Chavez

\begin{tabular}{|c|c|c|c|c|c|}
\hline VARIABLES & $\begin{array}{c}\text { (1) } \\
\text { baseline }\end{array}$ & $\begin{array}{l}\text { (2) } \\
\text { narrow control } \\
\text { group }\end{array}$ & $\begin{array}{c}\text { (3) } \\
\text { vote share }\end{array}$ & $\begin{array}{c}\text { (4) } \\
\text { continuous } \\
\text { signal }\end{array}$ & $\begin{array}{c}\text { (5) } \\
\text { high signal }\end{array}$ \\
\hline after & $\begin{array}{c}-0.2256 * * * \\
(0.0168)\end{array}$ & $\begin{array}{c}-0.2476 * * * \\
(0.0253)\end{array}$ & $\begin{array}{c}-0.0503 * * * \\
(0.0036)\end{array}$ & $\begin{array}{c}-0.2188 * * * \\
(0.0173)\end{array}$ & $\begin{array}{c}-0.2279 * * * \\
(0.0166)\end{array}$ \\
\hline Globo City X After & $\begin{array}{c}-0.1117^{* * *} \\
(0.0391)\end{array}$ & $\begin{array}{c}-0.0897 * * \\
(0.0436)\end{array}$ & $\begin{array}{c}-0.0183^{* *} \\
(0.0091)\end{array}$ & & \\
\hline Signal X After & & & & $\begin{array}{c}-0.2218^{* * *} \\
(0.0599)\end{array}$ & \\
\hline Globo City (high) X After & & & & & $\begin{array}{c}-0.0926 * * \\
(0.0468)\end{array}$ \\
\hline Observations & 1,668 & 688 & 1,668 & 1,668 & 1,668 \\
\hline R-squared & 0.8370 & 0.8815 & 0.8474 & 0.8376 & 0.8368 \\
\hline
\end{tabular}

Table 7 
Vote shares: Placebo Timing

\begin{tabular}{lcccc}
\hline & $(1)$ & $(2)$ & $(3)$ & $(4)$ \\
VARIABLES & 1 year before & baseline & 2 years after & 5 years after \\
\hline After & $-0.0497^{* * *}$ & $-0.2256^{* * *}$ & -0.0245 & $-0.0731^{* * *}$ \\
& $(0.0183)$ & $(0.0168)$ & $(0.0151)$ & $(0.0196)$ \\
Globo City X After & -0.0337 & $-0.1117^{* * *}$ & $-0.1155^{* * *}$ & 0.0037 \\
& $(0.0393)$ & $(0.0391)$ & $(0.0279)$ & $(0.0330)$ \\
Observations & & & & \\
R-squared & 1,668 & 1,668 & 1,668 & 1,668 \\
\hline Robust standard errors in parentheses & 0.8001 & 0.8370 & 0.7999 & 0.8014 \\
*** $p<0.01, * *$ p $<0.05, * p<0.1$ & & & \\
standard errors clustered at the city level & & &
\end{tabular}

Table 8

Globovision signal and turnout

\section{(1)}

VARIABLES

\begin{tabular}{|c|c|c|c|c|}
\hline VARIABLES & $\begin{array}{l}\text { (1) } \\
\text { baseline }\end{array}$ & $\begin{array}{l}\text { (2) } \\
\text { narrow control } \\
\text { group }\end{array}$ & $\begin{array}{l}\text { (3) } \\
\text { continuous signal }\end{array}$ & $\begin{array}{c}\text { (4) } \\
\text { high signal }\end{array}$ \\
\hline after & $\begin{array}{c}0.0377^{* * *} \\
(0.0082)\end{array}$ & $\begin{array}{c}0.0479 * * * \\
(0.0109)\end{array}$ & $\begin{array}{c}0.0356 * * * \\
(0.0085)\end{array}$ & $\begin{array}{c}0.0383 * * * \\
(0.0081)\end{array}$ \\
\hline Globo City X After & $\begin{array}{c}0.0426 * * * \\
(0.0147)\end{array}$ & $\begin{array}{c}0.0324 * * \\
(0.0164)\end{array}$ & & \\
\hline Signal X After & & & $\begin{array}{c}0.0763 * * * \\
(0.0255)\end{array}$ & \\
\hline Globo City (high) X After & & & & $\begin{array}{c}0.0448 * * \\
(0.0191)\end{array}$ \\
\hline Observations & 1,668 & 688 & 1,668 & 1,668 \\
\hline R-squared & 0.9558 & 0.9670 & 0.9558 & 0.9558 \\
\hline
\end{tabular}

Signal X After

Globo City (high) X After

Table 9 


\section{A Appendix}

\section{A.1 Extension 1: Demand for Opposition Media}

In this extension, we embed our model of voter learning over the state (good or bad) into a model of collective action in which opposition to the government exhibits strategic complementary following, among others, Edmond (2013). In particular, voters receive a payoff of $\beta_{s}$ from participating in successful opposition against the government, with higher payoffs in the bad state, and we normalize payoffs from participating in successful opposition against the government in the good state to equal 0 (i.e. $\beta_{b}>\beta_{g}=0$ ). Since voters do not know the state of the world, their decisions are based upon expected payoffs and thus posterior probabilities of the bad state, given media reports. That is, expected benefits from a successful opposition equal $\operatorname{Pr}(s=b \mid r) \beta_{b}$ and these benefits are common across voters. Participating in opposition to the government, independent of success, entails an opportunity cost $\kappa$, which varies across individuals according to the cumulative distribution $F$. To summarize, participation in successful opposition yields an expected payoff equal to $\operatorname{Pr}(s=b \mid r) \beta_{b}-\kappa$, participation in unsuccessful opposition yields a payoff of $-\kappa$, and non-participation yields a payoff of 0 , regardless of collective action. Finally, in order for opposition to be successful, a fraction $f$ of the population must participate.

Given all of this, an equilibrium with successful opposition requires that at a fraction $f$ of the population must have positive expected net benefits from participation in successful opposition. That is, $F\left[\left(\operatorname{Pr}(s=b \mid r) \beta_{b}\right]>f\right.$. We begin with the natural assumption that, in the absence of censorship $\left(\pi_{c}=0\right)$, opposition occurs in equilibrium only when the media publishes bad reports. Recall that $\operatorname{Pr}(s=b \mid r=$ $b)=1$ and that, in the absence of censorship, $\operatorname{Pr}(s=b \mid r=\phi)=\pi_{b}$. This assumption can thus be written as:

$$
\begin{gathered}
F\left(\beta_{b}\right)>f \\
F\left(\pi_{b} \beta_{b}\right)<f
\end{gathered}
$$

The first condition states that successful opposition will occur when voters know that the state is bad, and the second condition states that opposition will not occur when the media does not receive a signal. Thus, voters value being able to distinguish between cases in which the media receives no signal and cases in which the media receive a bad signal. Given this, censorship is bad for voters as it combines into non- 
reports cases in which the media receive no signal and cases in which the media receive a bad signal. Marginal increases in the degree of censorship $\left(\pi_{c}\right)$ from zero result in no changes in the equilibrium conditions (i.e., successful opposition only when the media publishes bad reports) but reduce the likelihood of bad reports. Thus, censorship reduces the probability of collective action. This is good for the government, and indeed a government attempting to minimize collective action will increase censorship probabilities until the marginal participant is indifferent between participating and not participating when receiving no media report. That is, $F\left[\left(\operatorname{Pr}(s=b \mid r=\phi) \beta_{b}\right]=f\right.$. But this will clearly be bad for voters, who are now less likely to lead an successful opposition under the bad state of the world even though they would benefit from doing so. In this sense, voters have a demand for uncensored opposition media and are worse off as the degree of censorship increases.

\section{A.2 Extension 2: Informative signals about the Media Environment}

Suppose that, prior to receiving a media report, voters receive information about the media environment. That is, voters receive an additional signal $(\theta=c$ or $\theta=u)$, which equals the media environment with probability $\rho$. That is, $\operatorname{Pr}(\theta=m)=\rho$. We assume that $\rho>0.5$ and $\rho<1$. Then, after receiving this signal, voters first update over the media environment as follows:

$$
\operatorname{Pr}(m=c \mid \theta=c)=\frac{\rho \pi_{c}}{\rho \pi_{c}+(1-\rho)\left(1-\pi_{c}\right)}
$$

This is greater than $\pi_{c}$ so long as $\pi_{c}<1$. Likewise, upon observing a signal that the environment is uncensored, voters update as follows:

$$
\operatorname{Pr}(m=c \mid \theta=u)=\frac{(1-\rho) \pi_{c}}{(1-\rho) \pi_{c}+\rho\left(1-\pi_{c}\right)}
$$

This is less than $\pi_{c}$ so long as $\pi_{c}<1$. An important result is that both probabilities are increasing in $\pi_{c}$ so long as the signal is not perfectly informative $(\rho<1)$. That is,

$$
\begin{aligned}
& \frac{\partial \operatorname{Pr}(m=c \mid \theta=c)}{\partial \pi_{c}}=\frac{\rho(1-\rho)}{\left[\rho \pi_{c}+(1-\rho)\left(1-\pi_{c}\right)\right]^{2}}>0 \\
& \frac{\partial \operatorname{Pr}(m=c \mid \theta=u)}{\partial \pi_{c}}=\frac{\rho(1-\rho)}{\left[(1-\rho) \pi_{c}+\rho\left(1-\pi_{c}\right)\right]^{2}}>0
\end{aligned}
$$


This result reflects the fact that, so long as the signal is not perfectly informative, there is still uncertainty over the media environment, and voters still place some weight on the prior probability that the media environment is censored $\left(\pi_{c}\right)$.

In this extension, are voters still systematically manipulated in the censored environment? Using the results from above, we have that:

$$
\operatorname{Pr}(s=b \mid r)=(1-p) \pi_{b}(1-q)+\left[p+(1-p) \pi_{b} q\right] \operatorname{Pr}(s=b \mid r=\phi)
$$

When calculating $\operatorname{Pr}(s=b \mid r=\phi)$ in this extended model, one must account for the two possible signals that could be received regarding the media environment. In the censored environment $(m=c)$, this can be written as:

$$
\operatorname{Pr}(s=b \mid r=\phi)=\rho \operatorname{Pr}(s=b \mid r=\phi, \theta=c)+(1-\rho) \operatorname{Pr}(s=b \mid r=\phi, \theta=u)
$$

Using Bayes rule, we have that:

$\operatorname{Pr}(s=b \mid r=\phi, \theta=c)=\frac{\operatorname{Pr}(r=\phi \mid s=b, \theta=c) \operatorname{Pr}(s=b, \theta=c)}{\operatorname{Pr}(r=\phi \mid s=b, \theta=c) \operatorname{Pr}(s=b, \theta=c)+\operatorname{Pr}(r=\phi \mid s=g, \theta=c) \operatorname{Pr}(s=g, \theta=c)}$

Using the fact that the signal about the media environment is independent of the state $(s)$, we have that $\operatorname{Pr}(s=b, \theta=c)=\operatorname{Pr}(s=b) \operatorname{Pr}(\theta=c)$ and that $\operatorname{Pr}(s=g, \theta=c)=\operatorname{Pr}(s=g) \operatorname{Pr}(\theta=c)$. Further, we can write $\operatorname{Pr}(r=\phi \mid s=b, \theta=c)=p+(1-p) \operatorname{Pr}(m=c \mid \theta=c) q$ and $\operatorname{Pr}(r=\phi \mid s=g, \theta=c)=p$. Plugging these four expressions into equation 12 , we have that:

$$
\operatorname{Pr}(s=b \mid r=\phi, \theta=c)=\frac{[p+(1-p) \operatorname{Pr}(m=c \mid \theta=c) q] \pi_{b}}{[p+(1-p) \operatorname{Pr}(m=c \mid \theta=c) q] \pi_{b}+p\left(1-\pi_{b}\right)}
$$

In a similar way, one can show that:

$$
\operatorname{Pr}(s=b \mid r=\phi, \theta=u)=\frac{[p+(1-p) \operatorname{Pr}(m=c \mid \theta=u) q] \pi_{b}}{[p+(1-p) \operatorname{Pr}(m=c \mid \theta=u) q] \pi_{b}+p\left(1-\pi_{b}\right)}
$$

Plugging equations 13 and 14 into equation 11 , we have that:

$\operatorname{Pr}(s=b \mid r=\phi)=\frac{\rho[p+(1-p) \operatorname{Pr}(m=c \mid \theta=c) q] \pi_{b}}{[p+(1-p) \operatorname{Pr}(m=c \mid \theta=c) q] \pi_{b}+p\left(1-\pi_{b}\right)}+\frac{(1-\rho)[p+(1-p) \operatorname{Pr}(m=c \mid \theta=u) q] \pi_{b}}{[p+(1-p) \operatorname{Pr}(m=c \mid \theta=u) q] \pi_{b}+p\left(1-\pi_{b}\right)}$ 
Finally, using this result, along with equations 9 and 10 , one can show that $\operatorname{Pr}(s=b \mid r)$ is less than $\pi_{b}$ so long as the signal over the media environment is not perfectly informative $(\rho<1)$ and so long as there is uncertainty over the media environment $\left(\pi_{c}<1\right) \cdot{ }^{30}$ Thus, voters continue to be systematically manipulated in the censored environment despite independent information on the media environment.

\section{A.3 Extension 3: Learning about Censorship from Past Media Reports}

In order to allow voters to learn about censorship from media reports, we assume that the media environment is stable, while the state of the world (good or bad) is independent over time. In this case, voters learn about the censoring environment from past media reports. In particular, the likelihood of the uncensored environment given no report equals:

$$
\operatorname{Pr}(m=c \mid r=\phi)=\frac{\operatorname{Pr}(r=\phi \mid m=c) \operatorname{Pr}(m=c)}{\operatorname{Pr}(r=\phi \mid m=c) \operatorname{Pr}(m=c)+\operatorname{Pr}(r=\phi \mid m=u) \operatorname{Pr}(m=u)}
$$

This can be written as:

$$
\operatorname{Pr}(m=c \mid r=\phi)=\frac{\left[p+(1-p) \pi_{b} q\right] \pi_{c}}{\left[p+(1-p) \pi_{b} q\right] \pi_{c}+p\left(1-\pi_{c}\right)}
$$

One can show that $\operatorname{Pr}(m=c \mid r=\phi)>\pi_{c}$, meaning that, upon observing no report, voters are more likely to believe that the media environment is censored and are less likely to believe that the media environment is uncensored. Conversely, upon observing a bad report, voters update as follows:

$$
\operatorname{Pr}(m=c \mid r=b)=\frac{\left[(1-p)(1-q) \pi_{b}\right] \pi_{c}}{\left[(1-p)(1-q) \pi_{b}\right] \pi_{c}+(1-p) \pi_{b}\left(1-\pi_{c}\right)}
$$

In this case, voters are less likely to believe that the media environment is censored and more likely to believe that the media environment is uncensored. That is, $\operatorname{Pr}(m=c \mid r=b)<\pi_{c}$. Finally, voters do not update with respect to the media environment upon observing a good report since these are not censored. That is, $\operatorname{Pr}(m=c \mid r=g)=\pi_{c}$.

To shed light on the dynamics and speed of learning, we conduct a numerical analysis in which we assume that the bad state occurs with probability 0.4 , that media outlets receive signals with probability 0.5 , that the censored environment occurs with probability 0.4 , and, finally, that bad signals are censored

\footnotetext{
${ }^{30}$ This result again follows from the fact that $\operatorname{Pr}(s=b \mid r)=\pi_{b}$ when $\pi_{c}=1$ and that $\operatorname{Pr}(s=b \mid r=\phi)$ is increasing in $\pi_{c}$ so long as $\rho<1$, meaning that voter perceptions of the bad state decrease as the likelihood of the censored media falls below 1 . This follows from the fact that both posterior probabilities of the censored environment are increasing in the prior probability that the media environment is censored $\left(\pi_{c}\right)$ and that voter beliefs over the bad state are increasing in these posterior probabilities.
} 
by the government in the censored environment with probability 0.7 . Then, we simulate the model 100,000 times and across 100 time periods. Whether or not the state is censored is stable and thus voters can learn about this from both current and previous reports over time. Whether the state of the world is bad, by contrast, is independent over time.

As shown in Figure 18, voters initially believe that they are in the uncensored environment with probability 0.6 and the censored environment with probability 0.4 . Given that bad reports are more likely in the uncensored environment and less likely in the censored environment, voters learn about the media environment from reports. As shown, in the censored environment, voter beliefs that the environment is uncensored approach zero after 100 media reports or, equivalently, time periods. In the uncensored environment, by contrast, voter beliefs that the environment is uncensored approach one after 100 media reports.

How does this learning about the media environment impact the ability of the government to manipulate voters through censorship. As shown in Figure 19, voters are initially more likely to believe that the bad state has occurred (by roughly 7 percentage points) when the media are censored, when averaged across all possible media reports in that environment. These differences fade, however, as perceptions approach the true probability of 0.4 following 100 media reports in both the censored and uncensored environments. Thus, censorship is effective at reducing voter perceptions of the bad state but only in the short run. In the long run, voters learn about the media environment from past reports and update accordingly. This is fully driven by how voters update following no report. As shown in Figure 20, when no report is received, voter perceptions of the bad state converge to the true probability of the bad state, 40 percent, when the media are not censored. When the media are censored, by contrast, voter beliefs of the bad state following no report converge to 53 percent, which is the true probability of the bad state given no report in the censored environment.

To summarize, censorship can systematically reduce voter perceptions of the bad state in the short run since voters are not aware of the media environment. In the long run, voters learn about the media environment from media reports and use this information when processing media reports. Thus, censorship reduces voter beliefs of the bad state but only in the short run. 


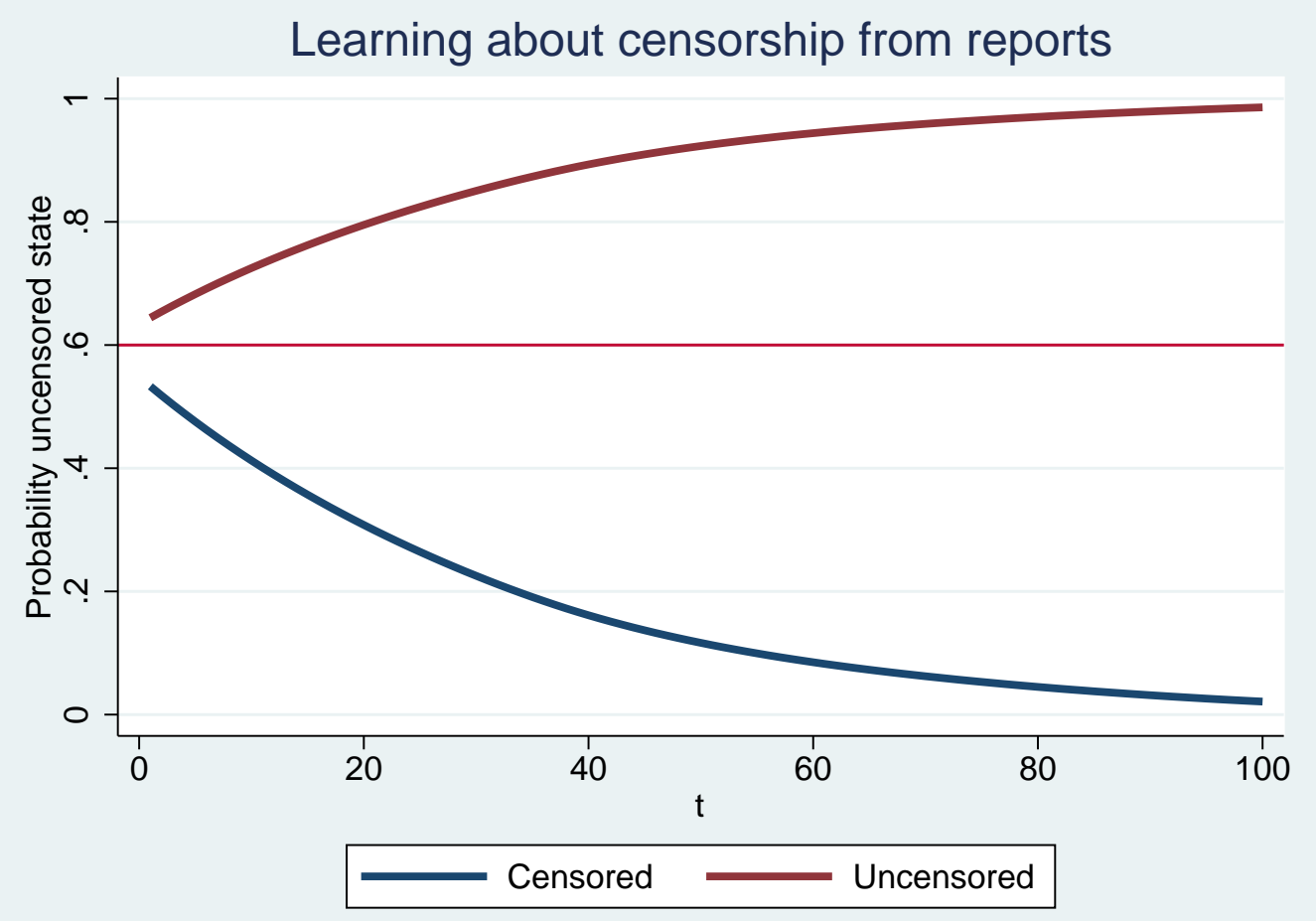

Figure 18

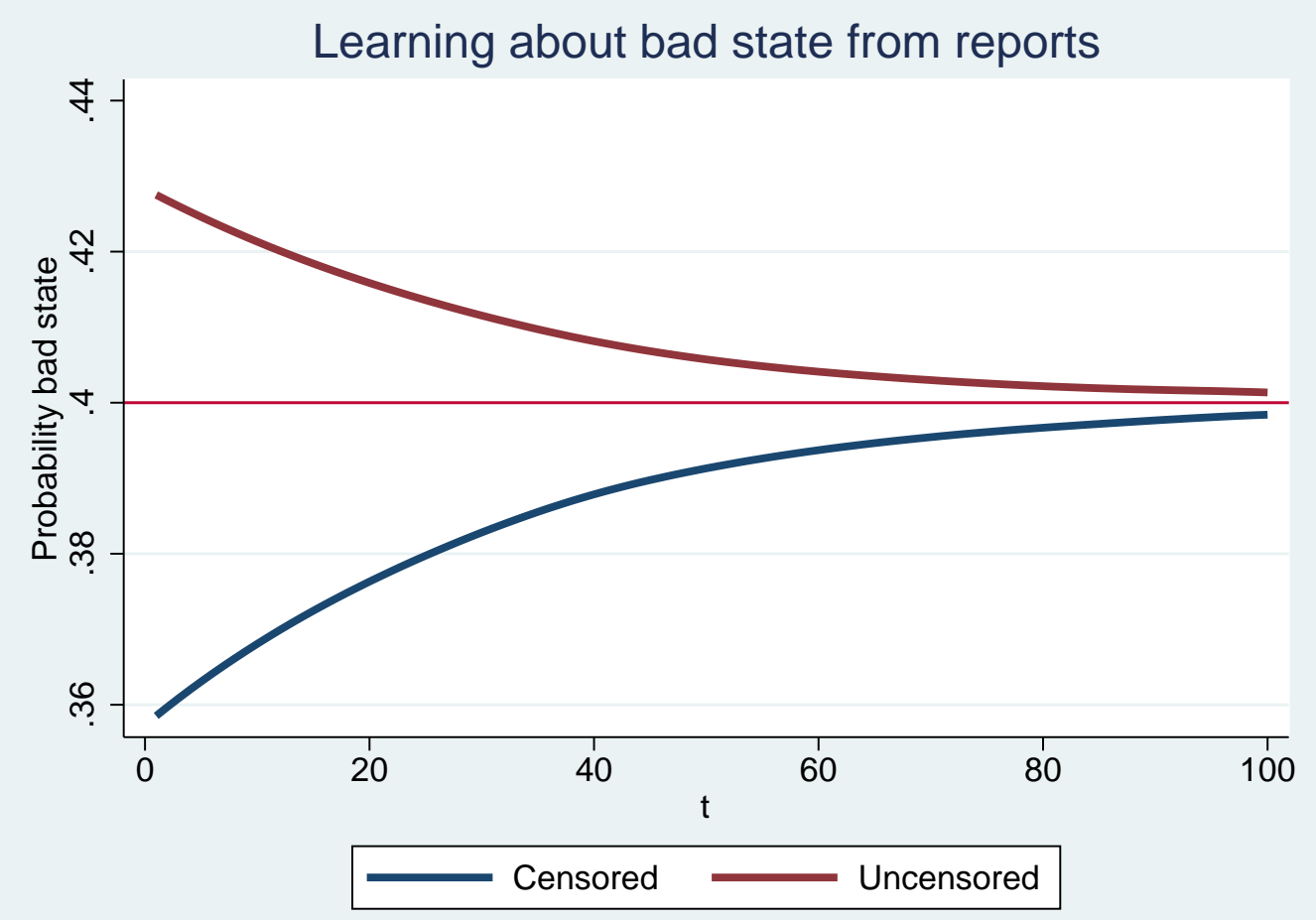

Figure 19 


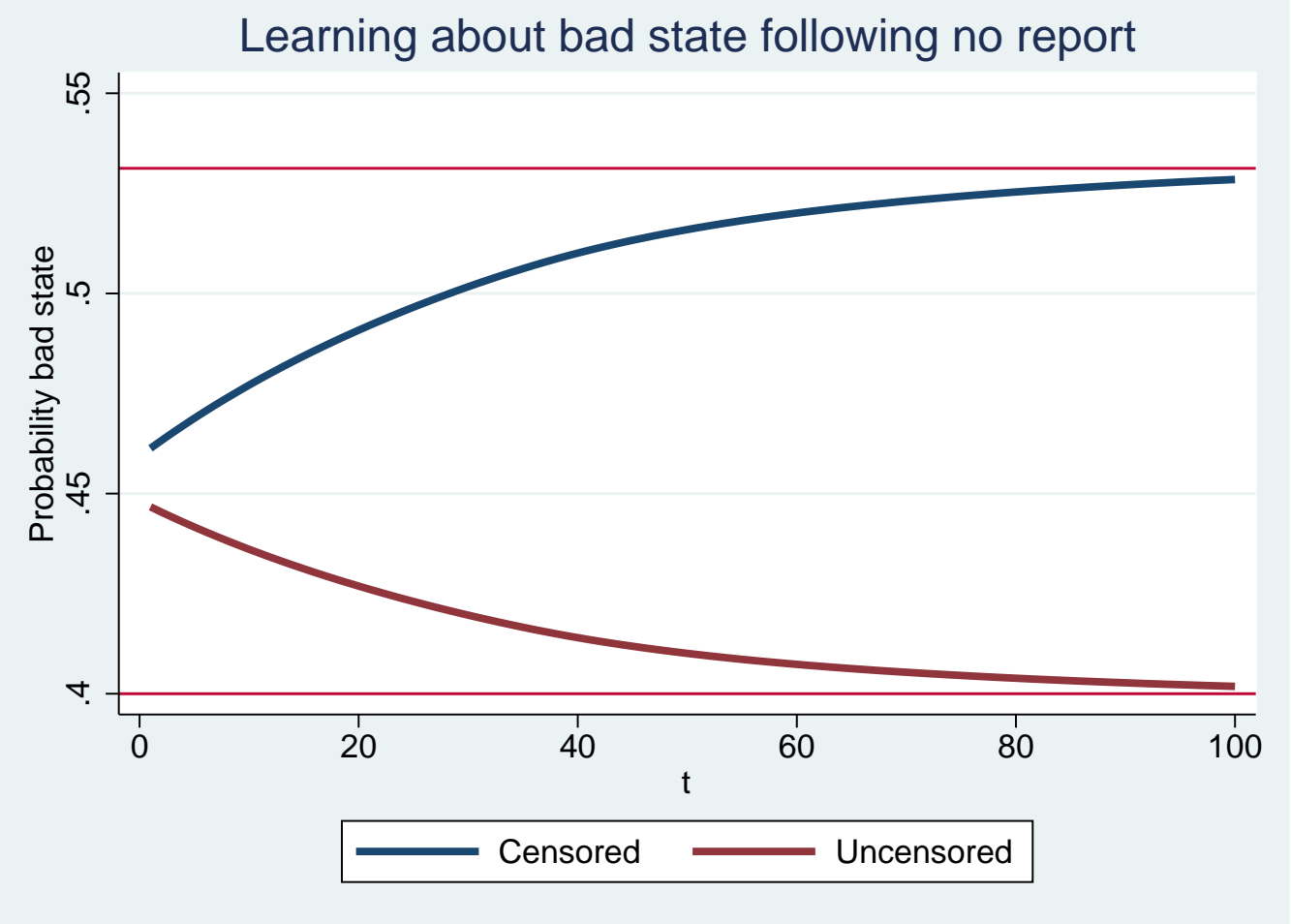

Figure 20

\section{A.4 Extension 4: Endogenous State Censorship}

Suppose that incumbents, knowing their type, choose the censorship environment. If censorship is effective, it follows that censorship should be maximal. Thus, we focus on incumbent choice between no censorship $(q=0)$ and full censorship $(q=1)$. We assume that censorship entails a cost equal to $C$. We construct an equilibrium in which bad types censor and good types do not. Then, given that the state is bad, we have that the probability of no report equals one; that is, $\operatorname{Pr}(r=\phi \mid s=b)=1$. Likewise, the probability of no report given that the state is good equals the probability of no signal being received by the media; that is, $\operatorname{Pr}(r=\phi \mid s=g)=p$. Given this, voters rationally update as follows after receiving no report:

$$
\operatorname{Pr}(s=b \mid r=\phi)=\frac{\pi_{b}}{\pi_{b}+p\left(1-\pi_{b}\right)}
$$

As in the baseline model, this exceeds $\pi_{b}$, meaning that voters update negatively about the candidate upon receiving no report, so long as there is uncertainty over the state $\left(\pi_{b}<1\right)$ and there is some likelihood that the media receives information $(p<1)$. It also exceeds the relevant expression in the baseline model (with $q=1$ ), due to the fact that voters now perceive the equilibrium link between censorship and the bad state. That is, upon seeing no report, they increase beliefs of censorship and hence their beliefs of the bad state. 
Likewise, we can show that censorship is an effective strategy when the state is bad. That is, average perceptions that the state is bad and when politicians engage in censorship equals:

$$
\operatorname{Pr}(s=b \mid r)=\frac{\pi_{b}}{\pi_{b}+p\left(1-\pi_{b}\right)}
$$

In the absence of censorship, by contrast, then $\operatorname{Pr}(s=b \mid r=\phi)=\pi_{b}$. In this case, average perceptions that the state is bad and when politicians do not engage in censorship equals:

$$
\operatorname{Pr}(s=b \mid r)=(1-p)+p \pi_{b}
$$

Then, one can show that average ex-post perceptions of the bad state are lower under censorship. Thus, due to these reputational benefits, the bad type will choose to censor so long as $C$ is sufficiently small. Likewise, the good type receives no benefits from censorship since bad signals are never received by the media outlets in this case.

\section{A.5 Extension 5: Censoring of good reports by opposition media}

Suppose that opposition media chooses to self-censor good reports about the government with probability $Q$. Then, we have that $\operatorname{Pr}(r=\phi \mid s=g)=p+(1-p) Q$. Then, voters update as follows upon receiving no report:

$$
\operatorname{Pr}(s=b \mid r=\phi)=\frac{\left[p+(1-p) \pi_{c} q\right] \pi_{b}}{\left[p+(1-p) \pi_{c} q\right] \pi_{b}+[p+(1-p) Q]\left(1-\pi_{b}\right)}
$$

Now voters may update in either direction upon receiving no report depending upon the relevant censoring probabilities $\left(\pi_{c}, q, Q\right)$.

Is censoring an effective government strategy? That is, does censorship systematically decrease the likelihood that voters believe the state is bad? To investigate this issue, consider the probability that voters believe that the state is bad averaged across media reports. This can be written as:

$$
\operatorname{Pr}(s=b \mid r)=\operatorname{Pr}(r=b)+\operatorname{Pr}(r=\phi) \operatorname{Pr}(s=b \mid r=\phi)
$$

In the censored environment, we have that $\operatorname{Pr}(r=b)=(1-p) \pi_{b}(1-q)$ and $\operatorname{Pr}(r=\phi)=p+(1-p)\left(\pi_{b} q+\right.$ $\left.\left(1-\pi_{b}\right) Q\right)$. Since the environment is unknown to voters, and using the results from above, this can be written as follows for the censored environment: 
$\operatorname{Pr}(s=b \mid r)=(1-p) \pi_{b}(1-q)+\left[p+(1-p)\left(\pi_{b} q+\left(1-\pi_{b}\right) Q\right)\right] \frac{\left[p+(1-p) \pi_{c} q\right] \pi_{b}}{\left[p+(1-p) \pi_{c} q\right] \pi_{b}+[p+(1-p) Q]\left(1-\pi_{b}\right)}$

As before, this is less than $\pi_{b}$ so long as $\pi_{c}<1$. So, the result that state censorship of bad reports is effective is robust to allowing opposition media to censor good reports. 